\title{
Experimental investigation of different fill materials in arch bridges with particular focus on Pearl-Chain Bridges
}

\author{
Lund, Mia Schou Møller; Hansen, Kurt Kielsgaard; Hertz, Kristian Dahl
}

Published in:

Construction and Building Materials

Link to article, DOI:

10.1016/j.conbuildmat.2016.07.089

Publication date:

2016

Document Version

Peer reviewed version

Link back to DTU Orbit

Citation (APA):

Lund, M. S. M., Hansen, K. K., \& Hertz, K. D. (2016). Experimental investigation of different fill materials in arch bridges with particular focus on Pearl-Chain Bridges. Construction and Building Materials, 124, 922-936.

https://doi.org/10.1016/j.conbuildmat.2016.07.089

\section{General rights}

Copyright and moral rights for the publications made accessible in the public portal are retained by the authors and/or other copyright owners and it is a condition of accessing publications that users recognise and abide by the legal requirements associated with these rights.

- Users may download and print one copy of any publication from the public portal for the purpose of private study or research.

- You may not further distribute the material or use it for any profit-making activity or commercial gain

- You may freely distribute the URL identifying the publication in the public portal 


\title{
Experimental investigation of different fill materials in arch bridges with particular focus on Pearl-Chain Bridges
}

\author{
M.S.M. Lund*, K.K. Hansen**, K.D. Hertz \\ Technical University of Denmark, Department of Civil Engineering, Brovej 118, DK-2800 Kgs. Lyngby, Denmark
}

\begin{abstract}
Pearl-Chain Bridge technology is a recently developed prefabricated arch solution for road and railway bridges allowing faster, more environmentally friendly, and cheaper bridge construction. This study compared the strength and durability properties of three different types of fill material to find the most optimal fill for Pearl-Chain Bridges. Sub-base gravel, cement-stabilized gravel, and pervious concrete were tested with respect to compressive strength, stiffness, splitting tensile strength, permeability, freezethaw durability, and shrinkage. This paper summarizes the advantages and disadvantages of implementing the different types of fill material in arch bridges, particularly in Pearl-Chain Bridges.
\end{abstract}

Keywords: Arch bridge, Cement-stabilized gravel, Fill material, Pearl-Chain Bridge, Pervious concrete, Sub-base gravel

\section{Introduction}

The fill material resting on the arch in closed-spandrel arch bridges is an important part of the construction with respect to the bridge's structural system and the durability. Bridges are designed for a service lifetime of a minimum of 100 years, whereas all other constructions are designed for only 50 years [1]. This length of time places certain requirements on the materials used in bridges, including the fill material. A typical closed-spandrel arch bridge consists of the arch structure itself (made of concrete or masonry), spandrel walls, and a fill material, as shown in Figure 1.

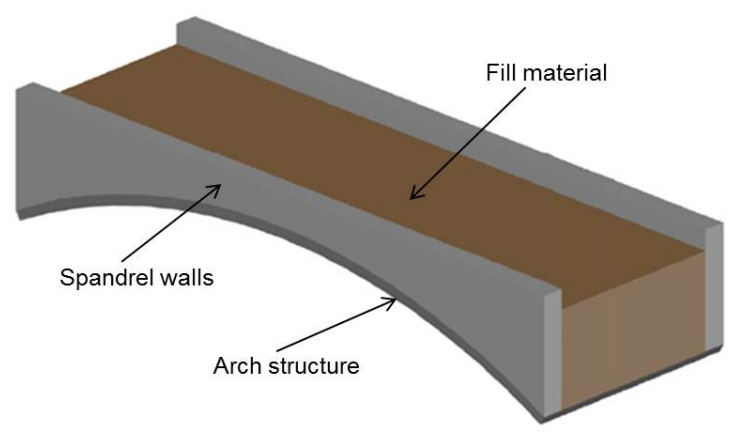

Figure 1: Typical closed-spandrel arch bridge construction with arch structure, fill material, and spandrel walls to retain the fill.

The static system of an arch bridge is based on the arch being in constant compression, first of all because of the consid-

\footnotetext{
*Corresponding author. Tel.: +45 45251752

** Tel.: +4545251826

Email addresses: msml@byg.dtu.dk (M.S.M. Lund), kkh@byg.dtu.dk (K.K. Hansen), khz@byg.dtu.dk (K.D. Hertz)
}

erable dead load from the fill material. Even when the arch is exposed to tensile stresses, such as from traffic loads, the compression force in the arch arising from the dead load of the fill is so large that the resulting force is most often also a compression force. Thus, reinforcement is rarely found in old masonry arches, such as the ancient Roman viaducts, and many of these arch constructions still exist 2,000 years after they were constructed, which bears witness of the superiority of this type of construction. However, the fill material in arch bridges is more than dead load ensuring stabilization of the arch; it also supports the road surface and in arch constructions with a large rise/span ratio, the fill contributes to the load carrying capacity of the arch structure through soil-structure interaction in which the passive soil pressure on the arch structure helps resist the horizontal forces from the load [2]. Until now, fill has only transferred vertical traffic loads from the road surface to the arch, and does so for the present Pearl-Chain Bridge research project described in Section 1.2.4; however, during the project the inventor of Pearl-Chain structures, Kristian Hertz, discovered a possibility of increasing the load-bearing capacity of the arch bridge by incorporating the fill as a structural part of a new design, which he calls a "sandwich arch bridge" (see Section 1.2.4).

Throughout history, various types of fill have been used worldwide, depending on several factors, such as economic considerations and the static system of the arch bridge. Typical types of fill can be divided into two categories:

- Granular (unbound) materials including soil $[3,4,5]$

- Cementitious (bound) materials [6, 7]

The fill material itself is a vulnerable part of the construction. Fill made from poor quality material or with a lack of compaction is sensitive to deterioration and defects [3]. Water 
trapped in the fill because of bad drainage or poor permeability can cause problems during winter when the bridge is exposed to freezing from below, above, and from the sides. Negative temperatures of the surrounding air create a freezing front that moves through the fill, and if the fill material is granular and water is trapped in it, ice crystals form and coalesce into ice lenses that can cause frost heaving. The expansion of the fill due to frost heaving will damage the construction by either exerting a high pressure on the spandrel walls or by cracking and deteriorating the road surface. Moreover, water trapped in granular fill reduces the strength of the fill material, which also results in the bridge's overall deterioration. Several examples show how old arch bridges have been strengthened by replacing old granular fill with concrete fill [3]. However, cementitious fill materials are also sensitive to frost exposure. Freezing and thawing can cause internal damages as well as scaling if the pore structure of cementitious materials is not properly designed; therefore, concrete used as fill material must be designed carefully to avoid this result.

\subsection{Fill used in Danish in situ arch bridges}

To create an overview of the fill material used in previous bridges, we reviewed the accessible drawings of Danish closed spandrel arch bridges. Among the approximately 11,300 Danish bridges registered as road- or railway-carrying, less than 5\% are closed-spandrel arch bridges. The number comprises all bridges owned by the Danish Road Directorate and the Danish railway traffic, but only $70 \%$ of the Danish municipal bridges, since these latter are not sufficiently registered. However, since most arch bridges are older, the amount of technical drawings is limited. For all bridges with accessible technical documentation, a well-grained, often coarse grained, gravel material was prescribed to be filled around the arch. In some cases this welldraining gravel material was only prescribed for the fill in the vicinity of $30 \mathrm{~cm}$ of the arch, and the remaining fill was either a well-compacted sand fill or a cement-stabilized gravel fill. We did not see any examples of concrete fill.

\subsection{Fill used in prefabricated arch bridge systems}

The arch is rarely chosen for in situ bridges nowadays because of the extensive scaffolding usually required to construct arch bridges. This requirement involves comprehensive preparatory work, intensive labor, and road closure for weeks because the scaffold and formwork take up a lot of space. Because it is no longer economically beneficial to cast in situ arch bridges, a number of different prefabricated arch bridge systems have been developed. However, currently none of these prefabricated arch systems have gained ground in Denmark. We will now review three examples of well-established prefabricated arch bridge systems that are all so-called closed-spandrel arch bridges that work on the principle of soil-structure interaction. Finally, we will present the newly developed Danish Pearl-Chain Bridge technology that can be constructed without application of expensive curved molds and erected quickly without unnecessarily disturbing traffic.

\subsubsection{The FlexiArch bridge system}

The Macrete FlexiArch bridge system was developed in Ireland, and currently more than 40 FlexiArch bridges have been constructed. The arch structure is made of unreinforced precast concrete voussoirs connected by a flexible polymeric geotextile bonded to the top of all elements. The arch is flat on the ground, but shapes when it is lifted [1]. Two different types of fill have been tested on the FlexiArch bridges: a low-strength concrete backfill and a granular backfill. When using granular backfill, the gradation of the gravel was found to have a large influence on the load capacity. A well-graded fill resulted in lower deflections and higher load capacity than fill that was not wellgraded. Developers of the FlexiArch system have not specifically defined a "well-graded fill"; however, they have found that the strength of FlexiArch bridges was much higher when using concrete backfill rather than granular backfill. Moreover, economical reasons urge the use of concrete backfill rather than granular because concrete needs no compaction, inhibits the ingress of flood water, and also allows the bridge to be used for traffic just a few days after installation [7].

\subsubsection{The TechSpan bridge system}

The TechSpan bridge system was developed in the United States, and currently more than 500 TechSpan bridges have been constructed. The superstructure is made of two-piece, funicular curve-shaped, precast arches that are lifted into place using a crane. The total width of the bridge depends on the number of arches placed next to each other. The arch is filled with a granular material. The fill material around the arch is divided into three zones. Zone 1 is select granular material placed $1.0 \mathrm{~m}$ around the perimeter of the arch structure. Compaction of the material in zone 1 may be achieved through a light walk. Zone 2 fill material is placed vertically and horizontally around zone 1 . Compaction of the material in zone 2 may be achieved with heavy compaction equipment without any vibration. Zone 3 is all remaining fill around the arch, with compaction achieved with heavy compaction equipment with vibration [4]. The type of fill used in zone 2 and 3 is not prescribed.

\subsubsection{The BEBO arch system}

The BEBO arch system was developed in Switzerland, and currently more than 800 BEBO arch bridges have been constructed. The arch construction is similar to that of the TechSpan arch. For smaller spans a single concrete element is used, but larger spans require two elements per arch. The description of the fill requirements for the BEBO arch system are more detailed compared with the FlexiArch and TechSpan systems. The fill is an integrated load-carrying part of the bridge structure, and therefore, must permanently fulfill that purpose. The filling operation creates one of the most severe loads experienced by the structure; hence, the operation must be carefully planned and realized. The fill material should be granular with angular grains, and should be well-graded. The material around the arch is divided into three zones. Zone A describes all material not included in zone $\mathrm{B}$ and $\mathrm{C}$. The material used in zone A should have properties and compaction procedures equal to that of normal road embankments. Zone B describes the fill 
material located $2.0 \mathrm{~m}$ around the perimeter of the arch from the footings of the arch and up to 3/4 of the height of the arch. The material used in zone B should be granular and should not exceed $75 \mathrm{~mm}$ in diameter. The gradation should fall within the limits in Figure 3 [5]. Granular materials with a high content of silt and clay are unacceptable for backfill in zone B, unless they are stabilized with cement to improve their strength. The water content should allow maximum compaction; hence it should be compacted a minimum of $98 \%$ of the maximum dry density as determined by the standard proctor test. The fill placed $0.3 \mathrm{~m}$ around the perimeter of the arch in zone A and B should be compacted only with hand-operated equipment. Zone $\mathrm{C}$ describes the road section and consists of gravel, asphalt, or concrete [5].

\subsubsection{The Pearl-Chain Bridge system}

The Pearl-Chain Bridge system was developed in Denmark after 2013, and currently only one of these bridges has been constructed. The Pearl-Chain arch is constructed of SuperLight Decks (SL-Decks) that are collected on a post-tensioning wire, like pearls on a string [8]. Each SL-Deck is given a slight inclination at the ends, and has a duct cast through it longitudinally. Thus, the Pearl-Chain arch is formed from plane elements. To simplify the assembly, the Pearl-Chain arch is placed on its side; when the SL-Decks are emplaced, self-compacting mortar joints are cast between the decks, after which the arch is post-tensioned [9]. Next, a crane tilts and lifts the arch and places it at the correct location [10]. The entire arch is constructed next to the road, and depending on the span and width of the bridge, the Pearl-Chain arch can be placed during a night. After installation of spandrel walls, the fill material is laid out, and the road surface is placed on the fill.

Especially for long bridge spans, it can be highly advantageous to apply the new concept of a "sandwich arch", where a pre-stressed concrete top plate above the fill exchanges forces with the arch through shear in the fill. It is therefore important that the fill material is able to transfer shear stresses for these future applications.

Compared with the FlexiArch, TechSpan, and BEBO arch systems, the rise/span ratio of the very first Pearl-Chain Bridge was considerably shallower, and the bridge did not work on the soil-structure interaction principle. Figure 2 shows a longitudinal cross-section of the bridge.

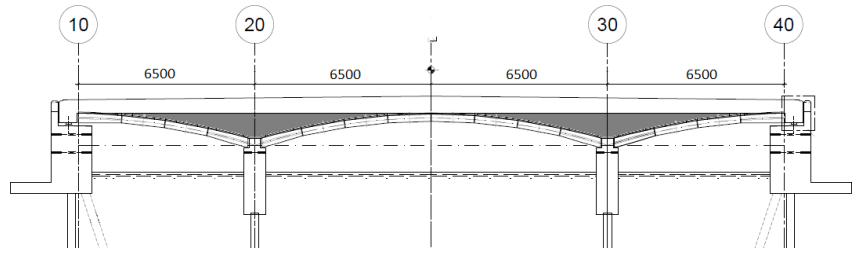

Figure 2: Longitudinal cross section of the very first Pearl-Chain Bridge constructed in Denmark in 2015. Dimensions are in mm. From: Lund et al. [11].

\subsection{Fill materials tested in the current study}

In this study, three different fill materials were tested to determine the most appropriate fill material for Pearl-Chain Bridges. The materials tested were sub-base gravel (SG), cement-stabilized gravel (CG), and Portland cement pervious concrete (PCPC). Sub-base gravel was tested because it is the most common fill material in Danish arch bridges, is inexpensive, and is typically considered a permeable material used for purposes in which the permeability of other types of gravel is too low. Moreover, the fines content of sub-base gravel is so low that the material is expected to be frost safe, avoiding frost heave [12]. Cement-stabilized gravel was tested because it is also relatively inexpensive due to its low cement content and also because it, opposed to sub-base gravel, is able to transfer shear stresses. Pervious concrete has a significant void content-typically 11-35\% [13]—providing excellent drainage. We tested pervious concrete because we expected its permeability properties to be improved compared to sub-base gravel and cement-stabilized gravel and because it is able to transfer shear stresses.

The strength and durability properties of the three different types of fill material were tested and compared for their compressive strength, Young's modulus, splitting tensile strength, permeability, freeze-thaw durability and shrinkage behavior. Different testing standards and procedures apply for different materials, which naturally caused some challenges for comparison of the materials.

\section{Experimental method}

\subsection{Material properties}

\subsubsection{Material properties for sub-base gravel}

Two types of Danish sub-base gravel were tested. Type SG8 had a gradation of $0-8 \mathrm{~mm}$ and type SG32 had a gradation of 0-32 mm. The two materials represent a geographical variation in the gradation of sub-base gravels in Denmark. Depending on where a Pearl-Chain Bridge is to be constructed, the gradation of a possible sub-base fill will vary. Figure 3 shows the gradation curves for the two sub-base gravels. SG8 had $1.1 \%$ particles with a diameter of less than $0.063 \mathrm{~mm}$ and for SG32 the fines content was $2.4 \%$.

\subsubsection{Material properties for cement-stabilized gravel}

One type of gravel, CG16, with a gradation of $0-16 \mathrm{~mm}$, as shown in Figure 3, was used to prepare the cement-stabilized gravel specimens. The gradation was thereby within envelope B in the Danish Standard (DS) 14277-1 [14], with an oversize of $7 \%$ on the $16 \mathrm{~mm}$ sieve. Envelope B describes wellgraded coarse aggregates with a limited fines content that can be successfully compacted to meet the requirements for hydraulically bound materials [14]. Moreover, the cement-stabilized gravel specimens were prepared with low alkali Portland cement, CEM I $42.5 \mathrm{~N}$, with a particle density of $3210 \mathrm{~kg} / \mathrm{m}^{3}$. 


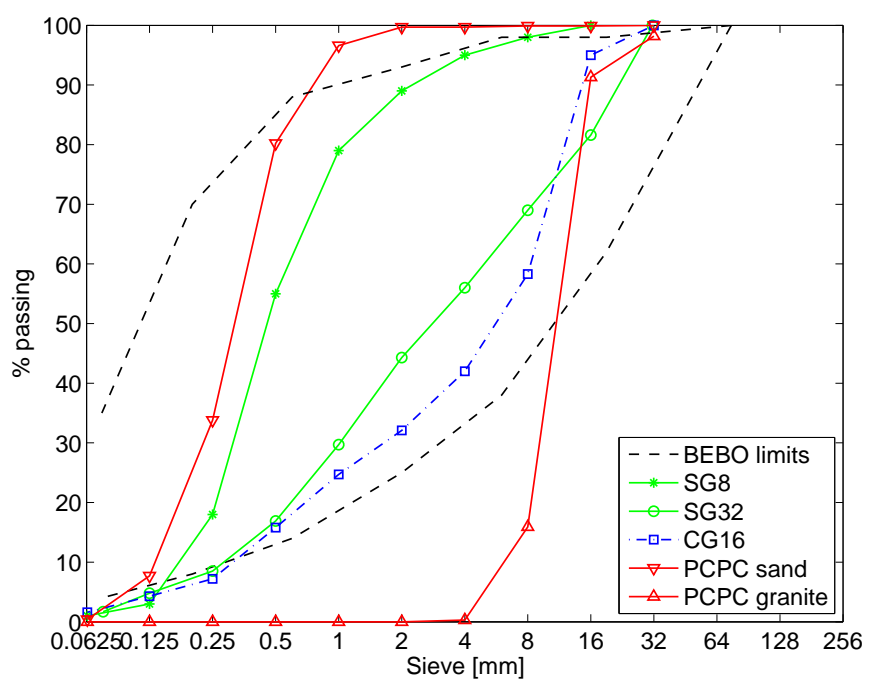

Figure 3: Gradation curves for sub-base gravel (SG), gravel used for cementstabilization (CG), and sand and granite used for pervious concrete (PCPC). The BEBO limits show the gradation of the fill material used in the BEBO arch system, zone B.

\subsubsection{Material properties for pervious concrete}

Pervious concrete consists of cement, water, sand and a single-sized coarse aggregate that is used to maximize the void content. Crushed granite was used as coarse aggregate. The granite had a particle density of $2,670 \mathrm{~kg} / \mathrm{m}^{3}$, absorption of $0.5 \%$, and a gradation of $8-16 \mathrm{~mm}$ as shown in Figure 3 . Concrete sand with a gradation of $0-2 \mathrm{~mm}$ as shown in Figure 3, a particle density of $2,630 \mathrm{~kg} / \mathrm{m}^{3}$ and absorption of $0.5 \%$, was used as fine aggregate. Portland cement, CEM II/A-LL $52.5 \mathrm{~N}$, with a particle density of $3,100 \mathrm{~kg} / \mathrm{m}^{3}$, and Danish fly ash type B4 with a particle density of $2,300 \mathrm{~kg} / \mathrm{m}^{3}$ also were used. Moreover a combined natural and synthetic air entrainment (AEA) was used.

\subsection{Mix designs}

\subsubsection{Mix design of sub-base gravel}

The optimal water content and maximum dry density was determined for gravels SG8 and SG32 using the vibrating table method, as described in the DS 13286-5 standard [15]. Thereby, the necessary amount of water for the two sub-base mixes and the maximum dry density were found as shown in Table 1.

Table 1: Optimal water content, $w_{\text {opt }}$, and maximum dry density, $\rho_{d, \text { max }}$, for sub-base gravel (SG) and gravel used for cement-stabilization (CG). SG8 and SG32 have a gradation of $0-8 \mathrm{~mm}$ and $0-32 \mathrm{~mm}$, respectively, as explained in Section 2.1.1. CG4\% and CG5\% contain $4 \%$ cement and 5\% cement, respectively, as explained in Section 2.2.2.

\begin{tabular}{l|cc|cc}
\hline & SG8 & SG32 & CG4\% & CG5\% \\
\hline$w_{\text {opt }}[\%]$ & 12.8 & 7.9 & 7.1 & 8.0 \\
$\rho_{d, \max }\left[\mathrm{kg} / \mathrm{m}^{3}\right]$ & 1,911 & 2,171 & 2,249 & 2,235 \\
\hline
\end{tabular}

In the mix design of sub-base gravel specimens the water content was one percentage point less than the optimal water content corresponding to water saturation determined from the vibrating table method as recommended in the Danish design guide for sub-base of sand and gravel [12]. Table 2 shows the mix designs for SG8 and SG32.

Table 2: Mix designs for sub-base gravel (SG), cement-stabilized gravel (CG) and pervious concrete (PCPC). SG8 and SG32 have a gradation of $0-8 \mathrm{~mm}$ and 0-32 mm, respectively, as explained in Section 2.1.1. CG4\% and CG5\% contain $4 \%$ cement and 5\% cement, respectively, as explained in Section 2.2.2.

\begin{tabular}{l|cccccc}
\hline & $\begin{array}{c}\text { Cement } \\
{\left[\mathrm{kg} / \mathrm{m}^{3}\right]}\end{array}$ & $\begin{array}{c}\text { Fly ash } \\
{\left[\mathrm{kg} / \mathrm{m}^{3}\right]}\end{array}$ & $\begin{array}{c}\text { Water } \\
{\left[\mathrm{kg} / \mathrm{m}^{3}\right]}\end{array}$ & $\begin{array}{c}\text { AEA } \\
{\left[\mathrm{kg} / \mathrm{m}^{3}\right]}\end{array}$ & $\begin{array}{c}\text { Gravel } \\
{\left[\mathrm{kg} / \mathrm{m}^{3}\right]}\end{array}$ & $\begin{array}{c}\text { Sand } \\
{\left[\mathrm{kg} / \mathrm{m}^{3}\right]}\end{array}$ \\
\hline $\mathrm{SG8}$ & - & - & 220 & - & $1,851 \dagger$ & - \\
$\mathrm{SG} 32$ & - & - & 154 & - & $2,143 \dagger$ & - \\
\hline CG4\% & 90 & - & 179 & - & $2,146 \dagger$ & - \\
$\mathrm{CG} \%$ & 113 & - & 160 & - & $2,134 \dagger$ & - \\
\hline PCPC & 340 & 68 & 105 & 5.3 & 1,300 & 121 \\
\hline
\end{tabular}

\subsubsection{Mix design of cement-stabilized gravel}

The cement contents for the cement-stabilized gravel specimens were chosen as $4 \%$ and $5 \%$ of the dry material in an attempt to design specimens corresponding to strength classes $\mathrm{C}_{5 / 6}$ and $\mathrm{C}_{12 / 15}$ with 28-day compressive cylinder strengths of $5 \mathrm{MPa}$ and $12 \mathrm{MPa}$, respectively [14]. For economic reasons, the lowest possible cement content for Pearl-Chain Bridges is desired. The optimal water content was determined from proctor tests in accordance with the DS 13286-2 standard [16] by including the influence of both cement contents on the compaction of the gravel [17]. The cement content was substituted with the equivalent amount of fly ash, since the particle size distribution of the two materials is similar and fly ash does not react with water. Thereby, we determined the necessary amount of water for the mixes. Table 1 shows the optimal water content and the maximum dry density of cement-stabilized gravel with $4 \%$ cement (CG4\%) and 5\% cement (CG5\%) determined from the proctor tests. Table 2 shows the mix designs for the cement-stabilized gravel specimens.

\subsubsection{Mix design of pervious concrete}

The pervious concrete mix was designed to have a waterto-cement (w/c) ratio of 0.29 , a fly ash-to-cement ratio of $20 \%$, and $9.5 \%$ of the mass of coarse aggregate replaced by sand [18]. Moreover, we designed it to have a void content of $17.5 \%$ and $6 \%$ entrained air. For Pearl-Chain Bridges the pervious concrete mix design should be kept as simple as possible for economic reasons. Therefore, for example, the mix design tested in this study did not include other additives than air entrainment. Table 2 shows the mix design.

\subsection{Preparation of specimens}

\subsubsection{Preparation of sub-base gravel specimens}

The sub-base gravel specimens were prepared by mixing sub-base gravel and water for 10 minutes in a pre-wetted compulsory mixer. Afterwards, we prepared the specimens as described in the American Society for Testing and Materials (ASTM) D5918-13 standard [19] with only a few deviations. 
The specimens were compacted in $150 \mathrm{~mm}$ high acrylic molds assembled from six cylindrical acrylic pieces, each with an inside diameter of $140 \mathrm{~mm}$ and a height of $25 \mathrm{~mm}$. A $1 \mathrm{~mm}$ thick butyl membrane with an outer diameter of $140 \mathrm{~mm}$ sealed the specimens inside the mold. A circular plate with a diameter of $140 \mathrm{~mm}$ placed was below the mold, and the membrane was stretched around the circular plate and the top of the mold, allowing room for the specimen to be compacted. To compact the specimens, we placed the mass of gravel corresponding to the inside volume of the acrylic mold in the mold in five loads of equal heights, applying 56 blows from a rammer to each load. For SG32, we also used vibration. After compaction, we saturated the specimens using capillary absorption by placing them in water reaching $50 \mathrm{~mm}$ up the sides of the specimen for three days. The compaction degree, defined as the ratio between the actual dry density of the specimen and the optimal dry density determined from laboratory tests, was above $97 \%$ for all specimens. A more detailed description of the preparation of the specimens is found in Lund et al. [20].

\subsubsection{Preparation of cement-stabilized gravel specimens}

The cement-stabilized gravel specimens were prepared by mixing gravel, low alkali cement, and water for three minutes in a pre-wetted compulsory mixer. The specimens were cast in split molds with a diameter of $150 \mathrm{~mm}$ and a height of $300 \mathrm{~mm}$, using the vibrating table compaction method, according to the European Standard (EN) 13286-50 [21]. The mass of the mixture corresponding to the inside volume of the mold was placed in the mold during compaction with a rammer. The minimum degree of compaction was $97 \%$, and therefore, in agreement with the specifications in the Danish general work specification for hydraulic bound layers [22]. After curing for one day at $20^{\circ} \mathrm{C}$, the molds were split and the specimens were cured in water at $20^{\circ} \mathrm{C}$ until they achieved an age of 28 days.

\subsubsection{Preparation of pervious concrete specimens}

The pervious concrete specimens were prepared by first mixing the aggregates and $5 \%$ of the cement for one minute in a pre-wetted compulsory mixer. This process was done to coat all aggregates with cement to improve the mixture's strength [13]. Afterwards, air entrainment mixed with water in the ratio 1:9 was added to the mix. Finally, fly ash, the remaining cement and water was added and mixed for three minutes. The mixture was allowed to rest for three minutes and then mixed for an additional two minutes. The workability of the mixture was considered good because it was possible to form a ball without the paste draining off [23]. The air content in the fresh pervious concrete was measured to $6 \%$ with a press-ur-meter, using boiled and then cooled, demineralized water to eliminate air bubbles in the water from affecting the reading. The specimens were prepared in molds $150 \mathrm{~mm}$ in diameter and $300 \mathrm{~mm}$ high, with a collar attached to enable overfilling before compaction. We determined the mass of pervious concrete that corresponded to the inside volume of the mold from the mix design density, and then placed the material in the mold in a single lift. By using a mass of $40 \mathrm{~kg}$ - corresponding to a pressure of $22.2 \mathrm{kPa}$ the specimen was compacted from above to a height of 300 mm. Hereby the cylinder achieved the mix design void content of $17.5 \%$; however, because the compaction was applied from above, there was a variation in void content within the cylinder. Thus, the void content of the bottom half and the top half of the cylinder varied between 9.3-9.8\% and 15.6-20.2\%, respectively, which meant that specimens cut from the different halves for permeability and freeze-thaw tests had different void contents. No vibration was used when placing the pervious concrete mix in the molds to avoid problems with cement paste draining off the aggregates and to better control the void content. After curing in the molds for one day at $20^{\circ} \mathrm{C}$, the molds were split and the specimens were cured in water at $20^{\circ} \mathrm{C}$ until they achieved an age of 28 days.

\subsection{Testing procedures}

\subsubsection{Determination of void content for pervious concrete}

We measured the void content of the hardened pervious concrete specimens using the water displacement method based on Archimedes' principle. We measured the mass of the cylinder under water and above water, after removing excess surface water with a wrung cloth and allowing the specimens to drain for 15 minutes. The void content, $P[\%]$, was calculated using the formula:

$$
P=\left(1-\frac{m-m_{s w}}{\rho_{w} V_{t o t}}\right) \times 100 \%
$$

where $m[\mathrm{~kg}]$ is the mass of the specimen above water, $m_{s w}[\mathrm{~kg}]$ is the mass of the specimen submerged in water, $\rho_{w}\left[\mathrm{~kg} / \mathrm{m}^{3}\right]$ is the water density, and $V_{\text {tot }}\left[\mathrm{m}^{3}\right]$ is the total volume of the specimen.

\subsubsection{Strength and stiffness test setup}

The 28-day compressive strength, the 28-day Young's modulus, and the 28-day splitting tensile strength were measured for cement-stabilized gravel specimens and pervious concrete specimens. For both materials, six specimens were measured in each test.

28-Day compressive strength and Young's modulus. For the cement-stabilized gravel specimens the compressive strength and Young's modulus were determined in agreement with the EN 13286-41 standard [24] and the EN 13286-43 standard [25], respectively. For pervious concrete, no standards exist regarding strength determination; therefore, we carried out the compression test as a combination of the procedure described for conventional concrete in the DS 12390-3 standard [26], and in the International Organization for Standardization (ISO) 6784 standard [27]. The compressive tests were performed on a TONI $3000 \mathrm{kN}$ loading machine with a load rate of 3 and $5 \mathrm{kN} / \mathrm{s}$ for cement-stabilized gravel specimens with $4 \%$ cement and $5 \%$ cement contents, respectively, and $7 \mathrm{kN} / \mathrm{s}$ for pervious concrete specimens. The strain was measured by installing a system with two rigid rings tightly mounted around the specimens, and two extensometers placed between the rings as shown in Figure 4a. 

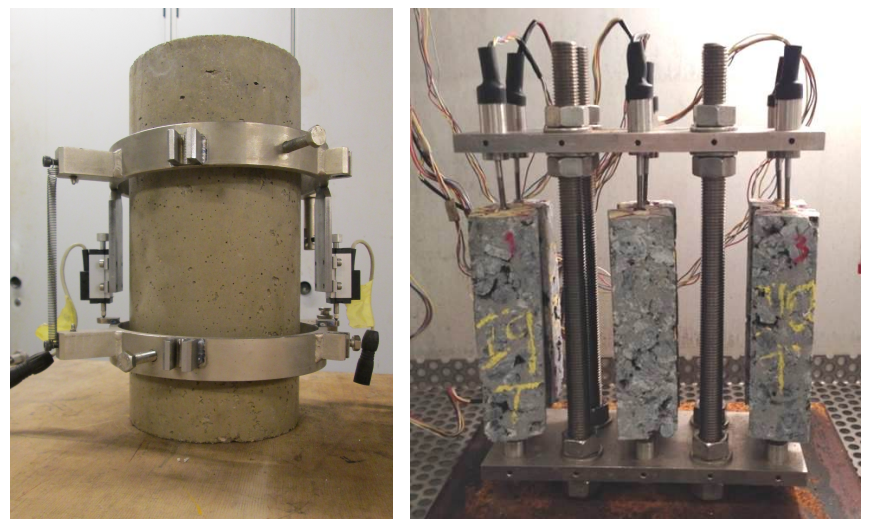

(a) Test setup for strain measure- (b) Shrinkage setup in climate chamber. ments of cement-stabilized gravel Six cement-stabilized gravel specimens and pervious concrete, shown for with dimensions of $4 \times 4 \times 15 \mathrm{~cm}^{3}$ were cement-stabilized gravel. Two tested. Three specimens had a cement rigid rings were each tightly fas- content of $4 \%$ and three specimens had tened to the specimen with three a cement content of $5 \%$.

screws, and two extensometers

were placed between the rings on opposite sides

Figure 4: Test setups for measurement of strain and shrinkage.

28-Day splitting tensile strength. For the cement-stabilized gravel specimens, the splitting tensile strength test was performed in agreement with the EN 13286-42 standard [28], and for pervious concrete it was performed in agreement with the standard for conventional concrete, ISO 4108 [29]. The splitting tensile strength tests were performed on a TONI 3000 $\mathrm{kN}$ loading machine with a load rate of $1.8 \mathrm{kN} / \mathrm{s}$ for cementstabilized gravel specimens and $4 \mathrm{kN} / \mathrm{s}$ for pervious concrete specimens.

\subsubsection{Permeability test setup}

Permeability of soils and other permeable materials typically is determined using one of two standard laboratory tests: the falling-head test and the constant-head test. The falling-head test is most suitable for materials with a low permeability, and therefore, we used this method to determine the permeability coefficient for sub-base gravel with a gradation of $0-8 \mathrm{~mm}$ and for cement-stabilized gravel. On the other hand, the constanthead test, which is described in the ASTM D2434-68 standard [30], is most suitable for materials with a medium to high permeability. Therefore, we used the constant-head test to determine the permeability coefficient for sub-base gravel with a gradation of $0-32 \mathrm{~mm}$ and for pervious concrete.

Falling-head test. In the falling-head test, the time difference, $t$ [s], between the initial and final water head difference, $h_{1}-h_{2}$ [m], is used to determine the permeability coefficient at $20^{\circ} \mathrm{C}$, $k_{20}[\mathrm{~m} / \mathrm{s}]$, using the formula:

$$
k_{20}=2.303 \frac{a L}{A t} \log _{10} \frac{h_{1}}{h_{2}} \frac{\eta_{T}}{\eta_{20}}
$$

where $a\left[\mathrm{~m}^{2}\right]$ is the cross-sectional area of the standpipe, $L[\mathrm{~m}]$ is the length of the specimen, $A\left[\mathrm{~m}^{2}\right]$ is the cross-sectional area of the specimen, $\eta_{T}[\mathrm{~Pa} \cdot \mathrm{s}]$ is the water viscosity at the temperature, $T\left[{ }^{\circ} \mathrm{C}\right]$, at which the test is conducted, and $\eta_{20}[\mathrm{~Pa} \cdot \mathrm{s}]$ is the water viscosity at $20^{\circ} \mathrm{C}$.

Figure 5 shows a principle sketch of the falling-head test setup used to determine the permeability coefficient for cementstabilized gravel.

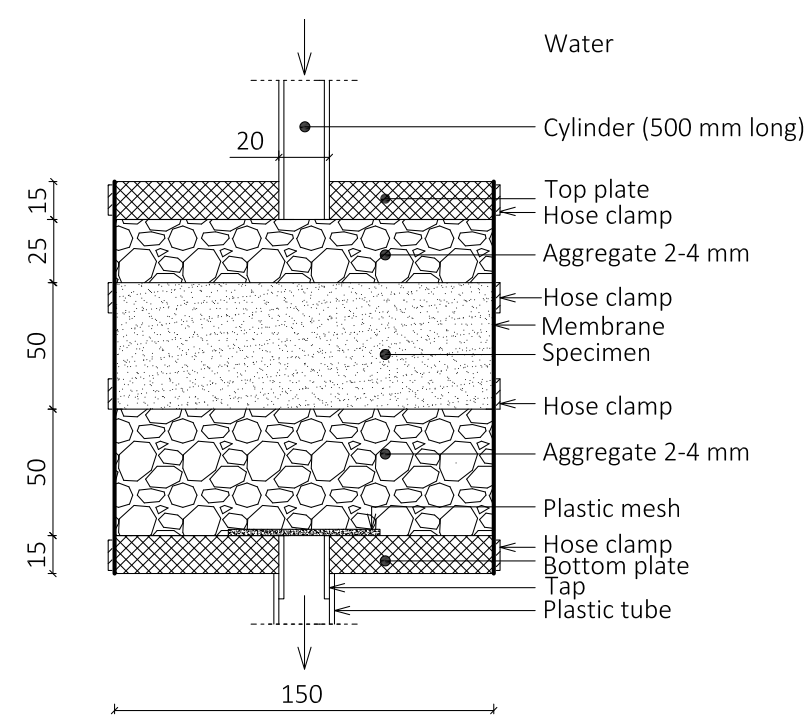

Figure 5: Test setup for falling-head test of cement-stabilized gravel specimens. Dimensions are in $\mathrm{mm}$.

The entire setup was sealed in a $3 \mathrm{~mm}$ thick rubber membrane with an inner diameter of $150 \mathrm{~mm}$. To assembly the setup, we first pulled the membrane over an aluminum bottom plate, $150 \mathrm{~mm}$ in diameter, and closed it tightly using a hose clamp. For the water outlet, a $20 \mathrm{~mm}$ hole was drilled at the center of the bottom plate and a plastic tube was connected. Next, a 50 $\mathrm{mm}$ layer of 2-4 $\mathrm{mm}$ aggregate was placed on the bottom plate inside the rubber membrane and compacted with a rammer to provide a firm and even surface. The aggregate was filled with water, and we adjusted the height of the plastic tube for water outlet to ensure the water level reached exactly the top side of the aggregate layer. Subsequently, a $50 \mathrm{~mm}$ high vacuum water saturated cement-stabilized gravel specimen, cut from the center of the $300 \mathrm{~mm}$ high cylinder specimens, was placed on the aggregate inside the rubber membrane. Using hose clamps, the rubber membrane and the specimen were tightened together to prevent water from escaping along the specimen sides. Hence, during the experiment, the aggregate below the specimen was filled with water and the underside of the specimen was not in contact with air. Thus, we prevented any menisci from forming in the cement-stabilized gravel specimens. A $25 \mathrm{~mm}$ layer of $2-4 \mathrm{~mm}$ aggregate was placed on the specimen and compacted lightly so that the surface was firm and even, after which it was filled with water. The permeability of the $2-4 \mathrm{~mm}$ aggregate layer was considerably greater than that of the specimen and did not influence the measurements. An aluminum top plate was placed on the aggregate and the rubber membrane was pulled around it, and closed tightly with a hose clamp. A $500 \mathrm{~mm}$ high plastic cylinder with a $16 \mathrm{~mm}$ inner diameter and 
a measurement scale along its height was fastened to a $20 \mathrm{~mm}$ hole drilled at the center of the top plate to control and measure the water inlet. For the $0-8 \mathrm{~mm}$ sub-base gravel, the setup was the same; however, the specimen tested was $125 \mathrm{~mm}$ high and was contained in the acrylic cylinder mold inside the rubber membrane.

For the cement-stabilized gravel specimens, the initial water head was $500 \mathrm{~mm}$ above the bottom of the specimen, and we monitored the decrease in water head during a period of at least seven days. Three different specimens were tested for cementstabilized gravel with both $4 \%$ cement and $5 \%$ cement, and the test was repeated four times for each specimen. For 0-8 mm sub-base gravel, the initial water head was $600 \mathrm{~mm}$ above the bottom of the specimen, and we monitored the decrease in steps of $50 \mathrm{~mm}$ down to $200 \mathrm{~mm}$ above the bottom of the specimen for three specimens.

Constant-head test. In the constant-head test a constant water head, $h[\mathrm{~m}]$, is established on top of a specimen with length $L[\mathrm{~m}]$ and cross-sectional area $A\left[\mathrm{~m}^{2}\right]$, and the water volume, $Q\left[\mathrm{~m}^{3}\right]$, penetrating the specimen during time $t[\mathrm{~s}]$ is used to calculate the permeability coefficient at $20^{\circ} \mathrm{C}, k_{20}[\mathrm{~m} / \mathrm{s}]$, using the formula:

$$
k_{20}=\frac{Q L}{A h t} \frac{\eta_{T}}{\eta_{20}}
$$

where $\eta_{T}[\mathrm{~Pa} \cdot \mathrm{s}]$ is the water viscosity at the temperature, $T\left[{ }^{\circ} \mathrm{C}\right]$, at which the test is conducted, and $\eta_{20}[\mathrm{~Pa} \cdot \mathrm{s}]$ is the water viscosity at $20^{\circ} \mathrm{C}$.

For 0-32 mm sub-base gravel, we used the same setup described for 0-8 mm sub-base gravel (Figure 5), except that the water level remained constant during the test period. Two constant water heads of $200 \mathrm{~mm}$ and $450 \mathrm{~mm}$ above the bottom of the specimen were tested for three specimens. For pervious concrete, we used the test setup shown in Figure 6.

Each $300 \mathrm{~mm}$ high pervious concrete specimen was cut in two halves of $150 \mathrm{~mm}$ in height, and both were tested. A 3 $\mathrm{mm}$ rubber membrane, with an inner diameter of $150 \mathrm{~mm}$, was pulled over a $150 \mathrm{~mm}$ high pervious concrete specimen and closed tightly with hose clamps to prevent water from escaping along the specimen sides. An acrylic cylinder with inner and outer diameters of $143 \mathrm{~mm}$ and $150 \mathrm{~mm}$ respectively, was placed on top of the specimen, inside the rubber membrane. The rubber membrane was tightly closed to the acrylic cylinder to provide a sealed connection. Two constant water heads of $270 \mathrm{~mm}$ and $500 \mathrm{~mm}$ above the bottom of the specimen were tested for six specimens.

\subsubsection{Freeze-thaw test setup}

Freeze-thaw test of sub-base gravel. The freeze-thaw test of sub-base gravel was performed in accordance with the ASTM D5918-13 standard [19]. The sub-base gravel specimen was installed in the freeze-thaw setup shown in Figure 7 and two specimens were tested for each type of sub-base gravel.

In the freeze-thaw setup the specimen was placed on an aluminum base plate that fed the specimen with water through the specimen's bottom. The base plate was connected to a tube

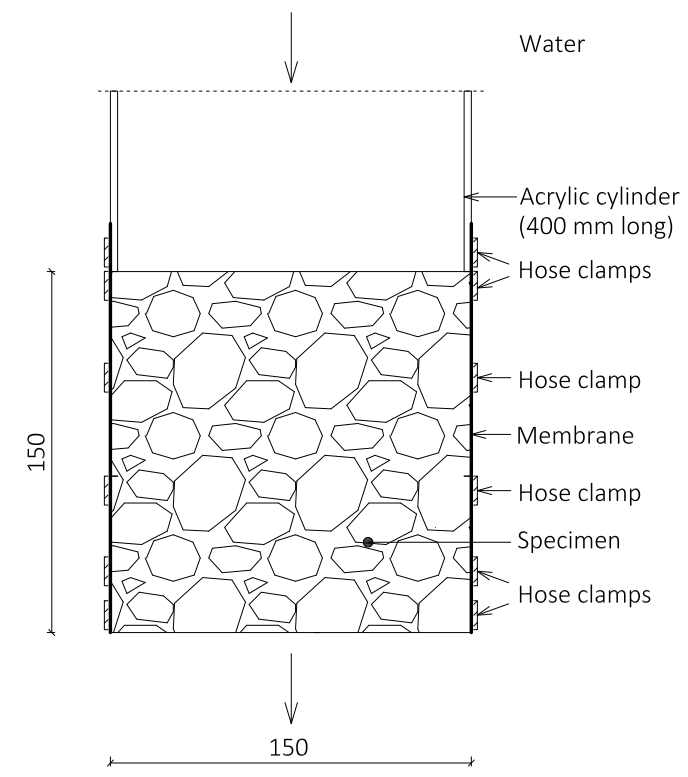

Figure 6: Test setup for constant-head test of pervious concrete. Dimensions are in $\mathrm{mm}$.

for water outlet and to a Mariotte water supply with a bubble tube that made it possible to adjust the water head to be $5 \mathrm{~cm}$ above the bottom of the specimen. The base plate was placed on an aluminum bottom temperature plate that controlled the temperature variation in the specimen from below. By connecting the bottom plate to a temperature bath with a thermostat and a pump unit, water was run through the bottom plate to obtain and maintain the desired temperature variation. The temperature variation of the bottom plate remained positive during the freeze-thaw test, as shown in Table 3.

Table 3: Temperature variation of the two plates with time during the freeze-thaw test of sub-base gravel.

\begin{tabular}{|c|c|c|c|c|}
\hline Day & $\begin{array}{c}t \\
{[\mathrm{~h}]}\end{array}$ & $\begin{array}{c}T_{\text {top plate }} \\
{\left[{ }^{\circ} \mathrm{C}\right]}\end{array}$ & $\begin{array}{c}T_{\text {bot. plate }} \\
{\left[{ }^{\circ} \mathrm{C}\right]}\end{array}$ & Comment \\
\hline 1 & 24 & 2.55 & 2.55 & Conditioning \\
\hline 2 & $\begin{array}{c}8 \\
16\end{array}$ & $\begin{array}{l}-3.45 \\
-12.45\end{array}$ & $\begin{array}{l}2.55 \\
0.50\end{array}$ & Freezing period \#1 \\
\hline 3 & $\begin{array}{c}16 \\
8\end{array}$ & $\begin{array}{l}11.55 \\
2.55\end{array}$ & $\begin{array}{l}2.55 \\
2.55\end{array}$ & $\begin{array}{l}\text { Thawing period \#1 } \\
\text { Stabilization }\end{array}$ \\
\hline 4 & $\begin{array}{c}8 \\
16\end{array}$ & $\begin{array}{l}-3.45 \\
-12.45\end{array}$ & $\begin{array}{l}2.55 \\
0.50\end{array}$ & Freezing period \#2 \\
\hline 5 & $\begin{array}{c}16 \\
8\end{array}$ & $\begin{array}{l}11.55 \\
2.55\end{array}$ & $\begin{array}{l}2.55 \\
3.00\end{array}$ & $\begin{array}{l}\text { Thawing period \#2 } \\
\text { Stabilization }\end{array}$ \\
\hline
\end{tabular}

$t=$ time $[\mathrm{h}], T_{\text {top plate }}=$ temperature of top plate $\left[{ }^{\circ} \mathrm{C}\right]$, $T_{\text {bot. plate }}=$ temperature of bottom plate $\left[{ }^{\circ} \mathrm{C}\right]$.

The temperatures in Table 3 correspond to the values in the ASTM D5918-13 standard [19], corrected with respect to the freezing point depression measured for the sub-base gravels. Moreover, the minimum temperature of the bottom plate was 


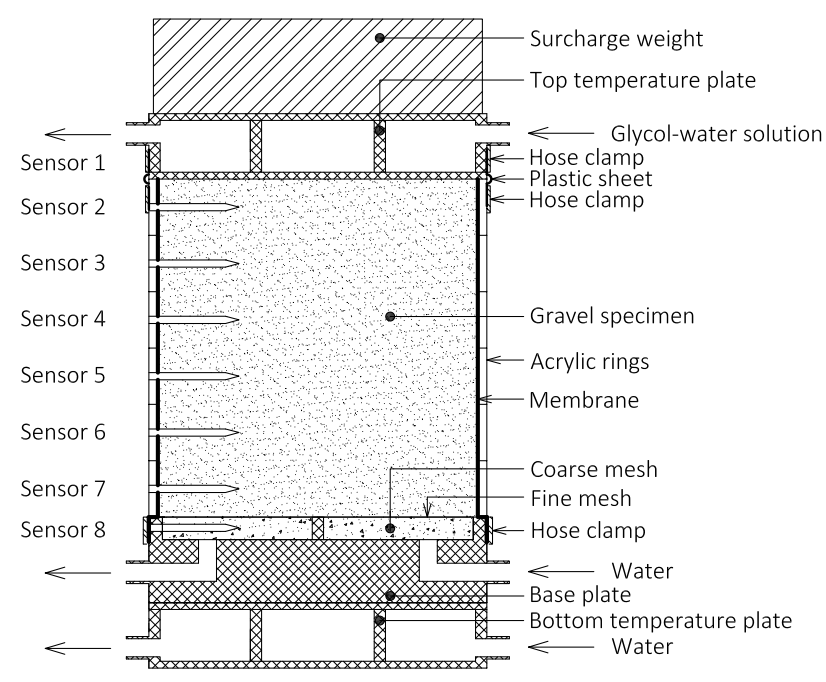

Figure 7: Setup for freeze-thaw test of sub-base gravel according to the ASTM D5918-13 standard [19]. Thermal insulation around the specimen is not shown.

increased from $0^{\circ} \mathrm{C}$ to $0.5^{\circ} \mathrm{C}$ because the thermostat's temperature band around the set point otherwise caused the temperature of the bottom plate to drop below $0^{\circ} \mathrm{C}$ by which the water below the specimen would freeze; however, this was assumed not to influence the results. An aluminum top temperature plate was placed on top of the specimen to control the temperature variation of the specimen from above. As with the bottom plate, the top plate was connected to a temperature bath that controlled the temperature by leading a glycol-water solution through the plate. As Table 3 indicates, freezing of the specimen was initiated from above. A surcharge weight of mass $5.5 \mathrm{~kg}$ was laid on the top plate. The entire setup was installed in a refrigerator at a temperature of $2^{\circ} \mathrm{C}$. However, during the test the temperature in the refrigerator varied between $-4^{\circ} \mathrm{C}$ and $8^{\circ} \mathrm{C}$. The entire setup and the tubes connecting the temperature plates to the temperature baths were covered in $25 \mathrm{~mm}$ thick insulation to prevent condensation. Finally, a small hole was made in the insulation on top of the surcharge weight to install an extensometer to measure vertical displacement with an accuracy of $4 \mu \mathrm{m}$.

During the freeze-thaw test, we measured the temperature variation in the specimen at six points by inserting temperature sensors in dip pipes into the specimen, as shown in Figure 7. We also measured the temperature in the water feed below the specimen, directly below the top plate, in the temperature baths, and inside the refrigerator.

It took five days to complete one freeze-thaw test, as shown in Table 3. After an initial 24-hour conditioning period, the specimens were exposed to two identical freeze-thaw periods. Each freeze-thaw period consisted of a 24-hour freezing period in which the temperature decreased in two steps, and a 16-hour thawing period followed by an 8-hour stabilization period in which the temperature was brought back to the original.

Freeze-thaw test of cement-stabilized gravel. Two cubes measuring $100 \times 100 \times 100 \mathrm{~mm}^{3}$ were cut from each of the cement- stabilized gravel cylinder specimens. One of the cubes was exposed to freezing and thawing; to serve as a reference, the other was stored in water at $20^{\circ} \mathrm{C}$ for later strength comparison. The freeze-thaw tests were carried out on specimens that were either saturated with water or with a $3 \% \mathrm{NaCl}$ solution. Fick's second law of diffusion was used to make a conservative estimate of the time needed for the chlorides to penetrate to the core of the specimen. Hence, the specimens to be saturated with salt water were soaked in a $3 \% \mathrm{NaCl}$ solution for 40 days before they were exposed to freezing and thawing. In total, six specimens were exposed to salt water and six specimens were exposed to demineralized water before freeze-thaw testing for both cement contents. After water saturation and salt water saturation, each specimen was wrapped in two layers of plastic and placed in a freezing cabinet. The temperature variation was chosen in correspondence with the prEN 13286-54 standard [31], and the core temperature of two cubes was measured during the test to ensure that the temperature variation of the specimens was as expected. Figure 8 shows the temperature variation of a cement-stabilized gravel specimen during a single freeze-thaw cycle that took 28 hours to complete. The test was terminated after 56 frost cycles.

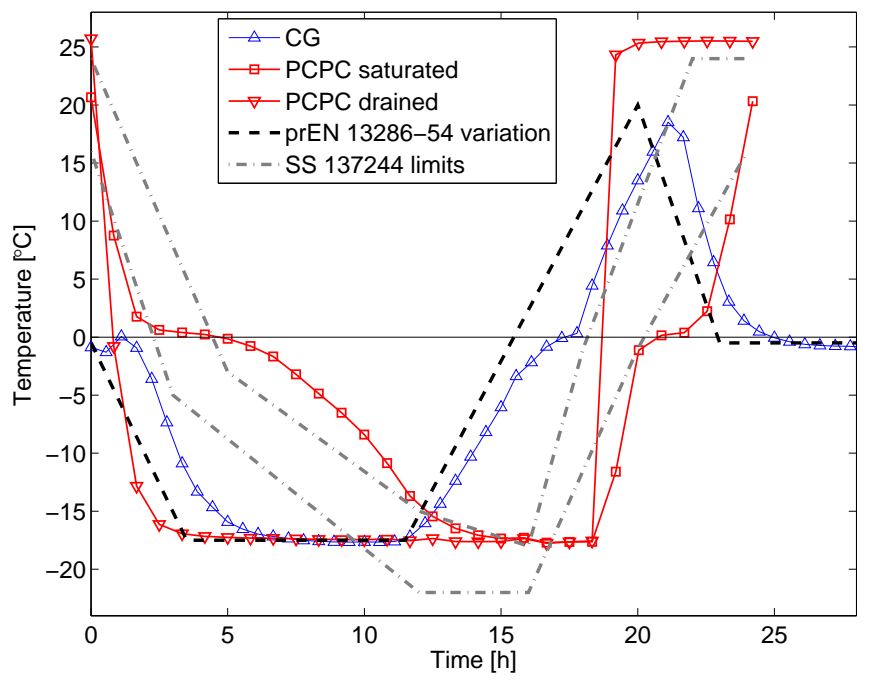

Figure 8: Core temperatures of cement-stabilized gravel specimens (CG) and pervious concrete specimens (PCPC) during a single freeze-thaw cycle. PCPC saturated $=$ pervious concrete specimens that are frozen in water and thawed in air. PCPC drained = pervious concrete specimens that are frozen and thawed in air. An acceptable temperature variation based on the prEN 13286-54 standard [31] is also shown together with the temperature limits for freeze-thaw test of conventional concrete, as described in the SS 137244 standard [32].

After every sixth frost cycle, we recorded the mass loss of each specimen and made a visual assessment of the specimen. Moreover, we measured the ultrasonic wave speed through the specimen. Finally, after 20 cycles and after 56 cycles, we determined the compressive strength for half of the specimens as well as for their references stored in water at $20^{\circ} \mathrm{C}$ during the frost tests.

Freeze-thaw test of pervious concrete. The freeze-thaw durability of pervious concrete is typically tested according to the 
same standards as conventional concrete; however, this exposure is typically considered to be too harsh and not representative of on-site behavior, since the drainage nature is not taken into account. In this study, we tested the freeze-thaw durability of the pervious concrete specimens according to these four methods:

1. Saturated method with demineralized water (SMW): specimens freezing and thawing in demineralized water.

2. Saturated method with salt water (SMS): specimens freezing and thawing in a $3 \% \mathrm{NaCl}$ solution.

3. Drained method with demineralized water (DMW): specimens freezing in air and thawing in demineralized water.

4. Drained method with salt water (DMS): specimens freezing in air and thawing in a $3 \% \mathrm{NaCl}$ solution.

We included the saturated method as a worst-case scenario, whereas, we considered the drained method to be a more realistic estimate of the actual behavior of pervious concrete due to its excellent drainage properties. However, in real life pervious concrete is not at any time expected to be submerged in water or salt water over a longer period of time and therefore the applied test procedures only represent an adapted reality.

Two cubes measuring $100 \times 100 \times 100 \mathrm{~mm}^{3}$ were cut from each of the pervious concrete cylinder specimens and exposed to freezing and thawing. 12 cubes were used for each of the four different methods, six of them representing the bottom part of the cylinders and six representing the top. Freezing of the specimens took place in a frost room at a temperature of $-20^{\circ} \mathrm{C}$ for 18 hours, and thawing took place in either demineralized water or in a $3 \% \mathrm{NaCl}$ solution with a constant temperature of $25^{\circ} \mathrm{C}$ for six hours. The salt water was changed every sixth cycle. Figure 8 shows the variation of the core temperature of a pervious concrete specimen exposed to the saturated method and of a pervious concrete specimen exposed to the drained method during a single frost cycle that took 24 hours to complete. Moreover, the figure shows the temperature limits prescribed in the Borås method for testing scaling of conventional concrete during freeze-thaw according to the Swedish Standard (SS) 137244 standard [32]. Because the boundary conditions in this study differed significantly from the Borås method, the temperature variation in the study also differed from the Borås method.

After every sixth frost cycle, the ultrasonic wave speed and the mass loss were recorded for each specimen. After 24 cycles and after 56 cycles the compressive strength was determined for half of the specimens. The compressive strength was also determined for reference specimens that were not exposed to freezing and thawing but were cast at the same time as the specimens that were. The test was terminated after 56 frost cycles.

\subsubsection{Shrinkage test setup}

We measured shrinkage only for cement-stabilized gravel. The specimens in the shrinkage tests were cut from the cylinder specimens and measured $40 \times 40 \times 150 \mathrm{~mm}^{3}$. The specimens were mounted in vertical position in a steel frame in a climate chamber with a temperature range from $-10^{\circ} \mathrm{C}$ to $60^{\circ} \mathrm{C}$ and a relative humidity range of $10-95 \%$. Extensometers with an accuracy of $2 \mu \mathrm{m}$ and a measuring range of $\pm 5 \mathrm{~mm}$ were used to measure displacements. Three specimens were tested for each cement content. The setup in the climate chamber is shown in Figure 4b. We conducted a total of four different tests to investigate the temperature dependent shrinkage and the moisture dependent shrinkage. In all tests the boundary conditions were reasonable estimates of the expected influence from the surrounding climate on the fill material in a bridge. In the first test, the relative humidity was fixed at $65 \%$ and the temperature varied between $5^{\circ} \mathrm{C}$ and $20^{\circ} \mathrm{C}$; in the second, the relative humidity was fixed at $65 \%$ and the temperature varied between $5^{\circ} \mathrm{C}$ and $40^{\circ} \mathrm{C}$; and in the third test, the temperature was fixed at $20^{\circ} \mathrm{C}$ and the relative humidity varied between $65 \%$ and $85 \%$. Finally, the temperature was fixed at $20^{\circ} \mathrm{C}$ and the relative humidity varied between $45 \%$ and $85 \%$ in the fourth test. In all four tests, the boundary conditions were first changed when a steady deformation was obtained. For tests with a variation in temperature, a steady deformation was obtained after three days; whereas it was obtained after seven days in tests with a variation in relative humidity. The steady deformation was determined when the variation in deformation was less than 0.005 per mile during a 12 hour period. Furthermore, we made two repetitions to support the observations [33].

We calculated the shrinkage induced by the variation in either temperature or relative humidity as the difference in strain between the measured steady strain at, for example, $5^{\circ} \mathrm{C}$ and $20^{\circ} \mathrm{C}$ for a fixed relative humidity. The strain calculations for a temperature variation were corrected with respect to the deformation of the steel frame that holds the specimen in position. This was done by estimating the coefficient of linear temperature expansion of the steel frame itself by inserting an Invar steel bar in the frame. Because Invar steel has a negligible coefficient of linear temperature expansion, we assumed the deformation measured over the Invar steel bar would correspond to the deformation of the steel frame. For the variation in temperature, the coefficient of linear temperature expansion was calculated using the formula:

$$
\varepsilon=\alpha \Delta T
$$

where $\varepsilon[-]$ is the strain, $\alpha\left[{ }^{\circ} \mathrm{C}^{-1}\right]$ is the coefficient of linear temperature expansion and $\Delta T\left[{ }^{\circ} \mathrm{C}\right]$ is the temperature difference.

\section{Results}

\subsection{Strength property results}

Table 4 shows the 28-day compressive strength, the 28-day Young's modulus, and the 28-day splitting tensile strength for cement-stabilized gravel and pervious concrete tested in this study and Young's modulus for sub-base gravel.

Danish road standards prescribe the value of Young's modulus for sub-base gravel as $0.150 \mathrm{GPa}$ [34]. For the cementstabilized gravel specimens, the 28-day compressive strength and the 28-day Young's modulus increased by $97 \%$ and $55 \%$, respectively, when increasing the cement content by $25 \%$. The 28 -day splitting tensile strength increased by $100 \%$. The strength properties of the pervious concrete specimens relate to specimens having an average void content of $18.1 \%$. 
Table 4: 28-day compressive strength $\left(f_{c}\right)$, Young's modulus $(E)$, and splitting tensile strength $\left(f_{s}\right)$, for sub-base gravel (SG), cement-stabilized gravel (CG) and pervious concrete (PCPC). SG8 and SG32 have a gradation of $0-8 \mathrm{~mm}$ and $0-32 \mathrm{~mm}$, respectively, as explained in Section 2.1.1. CG4\% and CG5\% contain $4 \%$ cement and 5\% cement, respectively, as explained in Section 2.2.2. $P$ is void content. Table values are based on Danish road regulations [34].

\begin{tabular}{l|ccc|c}
\hline & \multicolumn{3}{|c|}{ Test results } & Table values \\
\hline Material & $\begin{array}{c}f_{c} \\
{[\mathrm{MPa}]}\end{array}$ & $\begin{array}{c}E \\
{[\mathrm{GPa}]}\end{array}$ & $\begin{array}{c}f_{s} \\
{[\mathrm{MPa}]}\end{array}$ & $\begin{array}{c}E \\
{[\mathrm{GPa}]}\end{array}$ \\
\hline SG8 & - & - & - & 0.150 \\
SG32 & - & - & - & 0.150 \\
\hline CG4\% & 6.2 & 14.7 & 2.6 & 11.5 \\
CG5\% & 12.3 & 22.8 & 5.2 & 18.0 \\
\hline PCPC, $P=18.1 \%$ & 9.9 & 16.2 & 1.5 & - \\
\hline
\end{tabular}

\subsection{Permeability results}

Table 5 shows the results from the permeability tests.

Table 5: Permeability coefficients, $k_{20}$, for sub-base gravel (SG), cementstabilized gravel (CG) and pervious concrete (PCPC). SG8 and SG32 have a gradation of $0-8 \mathrm{~mm}$ and $0-32 \mathrm{~mm}$, respectively, as explained in Section 2.1.1. CG4\% and CG5\% contain 4\% cement and 5\% cement, respectively, as explained in Section 2.2.2. $P$ is void content.

\begin{tabular}{|c|c|c|}
\hline Material & $\begin{array}{c}\text { Average } \\
{[\mathrm{cm} / \mathrm{s}]}\end{array}$ & $\begin{array}{l}\text { Std. dev. } \\
{[\mathrm{cm} / \mathrm{s}]}\end{array}$ \\
\hline $\begin{array}{l}\text { SG8 } \\
\text { SG32 }\end{array}$ & $\begin{array}{c}7.3 \times 10^{-4} \\
35.1 \times 10^{-4}\end{array}$ & $\begin{array}{c}1.4 \times 10^{-4} \\
12.2 \times 10^{-4}\end{array}$ \\
\hline $\begin{array}{l}\mathrm{CG} 4 \% \\
\mathrm{CG} 5 \%\end{array}$ & $\begin{array}{l}7.2 \times 10^{-8} \\
1.4 \times 10^{-8}\end{array}$ & $\begin{array}{c}15.8 \times 10^{-9} \\
5.3 \times 10^{-9}\end{array}$ \\
\hline $\begin{array}{l}\text { PCPC, } P=9.3 \% \\
\text { PCPC, } P=20.2 \%\end{array}$ & $\begin{array}{c}7.4 \times 10^{-2} \\
69.3 \times 10^{-2}\end{array}$ & $\begin{array}{c}3.7 \times 10^{-2} \\
30.2 \times 10^{-2}\end{array}$ \\
\hline
\end{tabular}

The permeability coefficient of sub-base gravel was approximately five times larger when using gravel with a gradation of 0-32 mm compared with $0-8 \mathrm{~mm}$. For cement-stabilized gravel, the permeability coefficient of specimens containing $5 \%$ cement was approximately five times smaller than for specimens containing $4 \%$ cement. For pervious concrete, the permeability coefficient varied with the void content, as expected, and the permeability coefficient for specimens with $20.2 \%$ voids was approximately nine times larger than for specimens with $9.3 \%$ voids.

\subsection{Freeze-thaw durability results}

\subsubsection{Freeze-thaw results for sub-base gravel}

The frost susceptibility of gravels tested according to the ASTM D5918-13 standard [19] are assessed from the 8-hour heave rates, based on the deformation that occurred during the first and second freezing period. Table 6 shows the heave rates for both specimens for each of the sub-base gravels.

In climates where many annual frost cycles take place, such as Denmark's, the second heave rate should be used to evaluate the frost susceptibility according to the ASTM D5918-13
Table 6: 8-hour heave rates during frost cycles \#1 and \#2, and frost susceptibility classifications for sub-base gravels. SG8 and SG32 have a gradation of $0-8$ $\mathrm{mm}$ and 0-32 mm, respectively, as explained in Section 2.1.1.

\begin{tabular}{l|ccc}
\hline $\begin{array}{l}\text { Specimen } \\
\text { no. }\end{array}$ & $\begin{array}{c}\text { Heave rate \#1 } \\
{[\mathrm{mm} / \text { day }]}\end{array}$ & $\begin{array}{c}\text { Heave rate \#2 } \\
\text { [mm/day }]\end{array}$ & $\begin{array}{c}\text { Frost susceptibility } \\
\text { classification }\end{array}$ \\
\hline SG8-1 & 1.4 & 0.3 & Negligible \\
SG8-2 & 0.8 & 0.4 & Negligible \\
\hline SG32-1 & 7.1 & 5.4 & Medium \\
SG32-2 & 6.9 & 4.1 & Medium \\
\hline
\end{tabular}

standard [19]. On a frost susceptibility scale with classifications of negligible, very low, low, medium, high and very high, the frost susceptibility of sub-base gravel with a gradation of 0-8 mm was negligible; however, it was medium for sub-base gravel with a gradation of $0-32 \mathrm{~mm}$.

\subsubsection{Freeze-thaw results for cement-stabilized gravel}

During the freeze-thaw exposure of the cement-stabilized gravel specimens, the maximum mass loss was $0.5 \%$, considered insignificant. Also, there were no visual signs of degradation or scaling. However, we observed a decrease in the compressive strength as indicated in Figure 9. This figure compares the compressive strength of the specimens exposed to freezing and thawing for 20 days and 56 days with the reference compressive strength determined for specimens unexposed to freezing and thawing. The reference values represent an average of the reference compressive strengths determined after 20 cycles and 56 cycles since no difference between these strengths was observed. The results are divided between specimens with $4 \%$ and $5 \%$ cement.

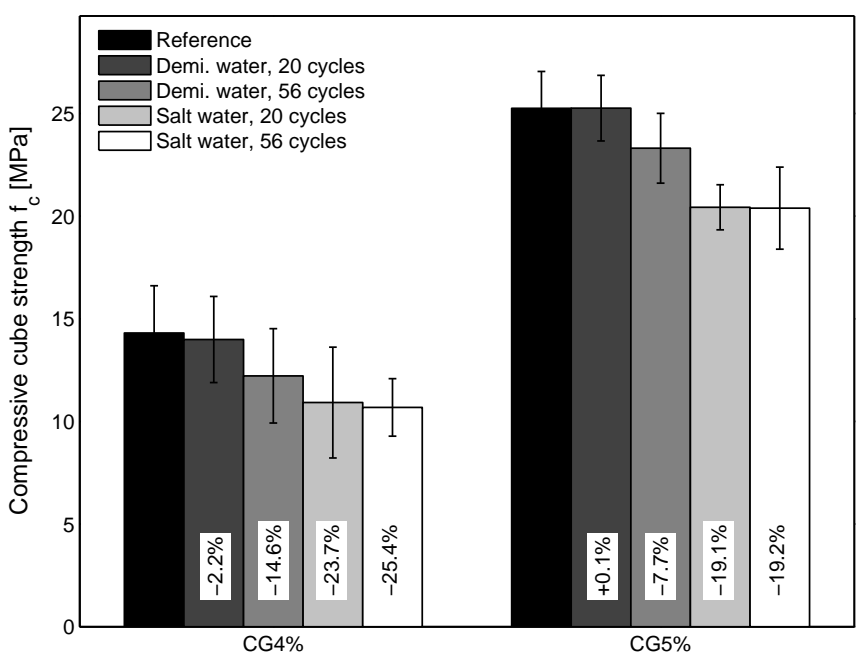

Figure 9: Compressive cube strength for cement-stabilized gravel specimens after 20 frost cycles and 56 frost cycles compared to reference specimens unexposed to freezing and thawing. The results are divided between specimens with $4 \%$ cement (CG4\%) and 5\% cement (CG5\%) exposed to either demineralized water or a $3 \% \mathrm{NaCl}$ solution.

Table 7 shows the relative change in wave speed between 0 and 56 frost cycles for the cement-stabilized gravel specimens 
with $4 \%$ cement and $5 \%$ cement either saturated with demineralized water or with a $3 \% \mathrm{NaCl}$ solution. For all specimens, the wave speed was approximately $4,100 \mathrm{~m} / \mathrm{s}$ before frost exposure, and therefore independent of the percentage of cement content.

Table 7: Relative decrease in wave speed, $v_{r e l}$, for cement-stabilized gravel specimens with $4 \%$ cement (CG4\%) and 5\% cement (CG5\%) saturated with demineralized water or a $3 \% \mathrm{NaCl}$ solution and exposed to 56 frost cycles.

\begin{tabular}{c|cc|cc}
\hline & \multicolumn{2}{|c|}{ Demi. water } & \multicolumn{2}{c}{ Salt water } \\
& CG4\% & CG5\% & CG4\% & CG5\% \\
\hline$v_{\text {rel }}[\%]$ & 41.8 & 22.9 & 64.5 & 46.2 \\
\hline
\end{tabular}

\subsubsection{Freeze-thaw results for pervious concrete}

The evaluation of freeze-thaw damages of pervious concrete is complicated by the already large influence of the void content on pervious concrete properties. A direct evaluation can be made only between specimens with the same void content.

We observed no change in the ultrasonic wave speed for the pervious concrete specimens exposed to freezing and thawing; however, a change in mass loss was detected. Figure 10 shows the mass loss for the pervious concrete specimens during the freeze-thaw test. The figure distinguishes specimens cut from the top of the cylinder from those cut from the bottom because they had a different void content. The average void content of the top and bottom specimens was $9.8 \%$ and $15.6 \%$, respectively. The figure also distinguishes specimens exposed to the saturated method from those exposed to the drained method, and specimens exposed to demineralized water from those exposed to salt water.

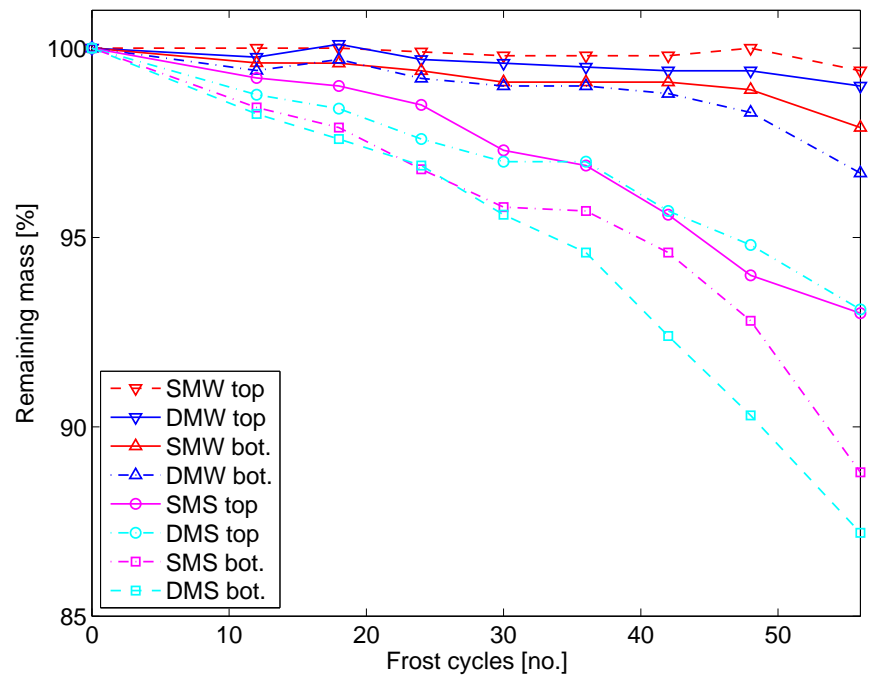

Figure 10: Remaining mass during freezing and thawing of pervious concrete specimens. SMW = Saturated method with demineralized water, DMW = Drained method with demineralized water, SMS $=$ Saturated method with salt water, and DMS $=$ Drained method with salt water, top $=$ top specimens with a void content of $9.8 \%$, bot. = bottom specimens with a void content of $15.6 \%$.

Figure 11 shows the appearance of two specimens after 0 frost cycles and 56 frost cycles with and without the presence of salt ions.

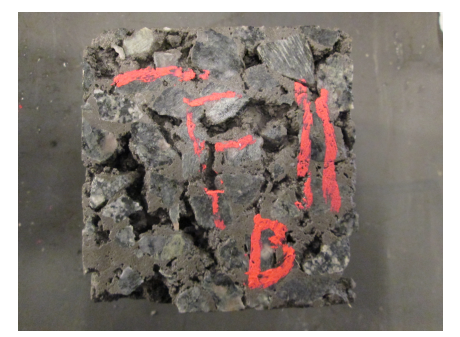

(a) Demineralized water, 0 cycles.

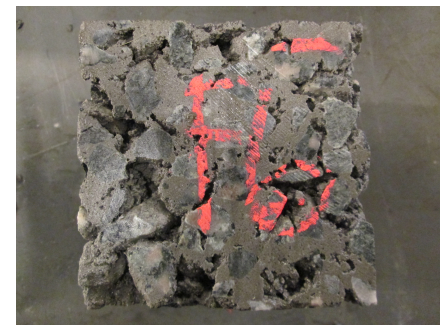

(c) $3 \% \mathrm{NaCl}$ solution, 0 cycles.

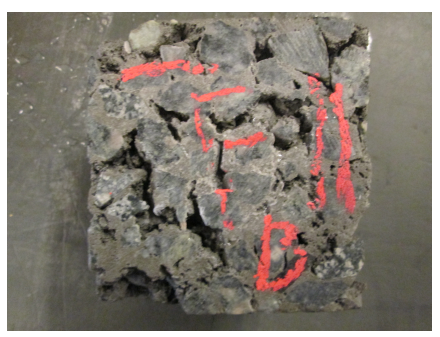

(b) Demineralized water, 56 cycles.

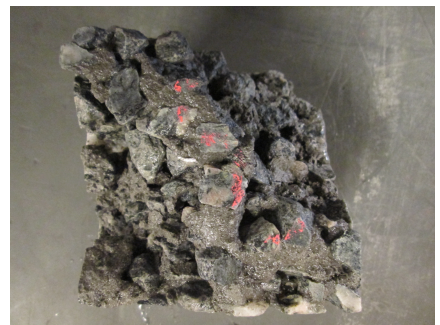

(d) $3 \% \mathrm{NaCl}$ solution, 56 cycles.
Figure 11: Visual appearance of pervious concrete cubes measuring $100 \times 100 \times$ $100 \mathrm{~mm}^{3}$ after 0 and 56 frost cycles. The specimens were freezing in air and thawing in either demineralized water or salt water.

\subsection{Shrinkage results}

Table 8 shows the strains and coefficients of linear temperature expansion for cement-stabilized gravel exposed to a variation in temperature and relative humidity.

Table 8: Strains, $\varepsilon$, and coefficients of linear temperature expansion, $\alpha$, for cement-stabilized gravel exposed to various boundary conditions. CG4\% and CG5\% contain $4 \%$ cement and 5\% cement, respectively, as explained in Section 2.2.2.

\begin{tabular}{cc|cc|cc}
\hline & & \multicolumn{2}{c|}{ CG4\% } & \multicolumn{2}{c}{ CG5\% } \\
\hline $\begin{array}{c}\text { RH } \\
{[\%]}\end{array}$ & $\begin{array}{c}T \\
{\left[{ }^{\circ} \mathrm{C}\right]}\end{array}$ & $\begin{array}{c}\varepsilon \\
{[-]}\end{array}$ & $\begin{array}{c}\alpha \\
{\left[{ }^{\circ} \mathrm{C}^{-1}\right]}\end{array}$ & $\begin{array}{c}\varepsilon \\
{[-]}\end{array}$ & $\begin{array}{c}\alpha \\
{\left[{ }^{\circ} \mathrm{C}^{-1}\right]}\end{array}$ \\
\hline 65 & $5-20$ & $1.5 \times 10^{-4}$ & $9.9 \times 10^{-6}$ & $1.7 \times 10^{-4}$ & $11.2 \times 10^{-6}$ \\
65 & $5-40$ & $3.5 \times 10^{-4}$ & $9.9 \times 10^{-6}$ & $4.0 \times 10^{-4}$ & $11.4 \times 10^{-6}$ \\
\hline $65-85$ & 20 & $3.6 \times 10^{-5}$ & - & $3.5 \times 10^{-5}$ & - \\
$45-85$ & 20 & $8.5 \times 10^{-5}$ & - & $8.4 \times 10^{-5}$ & - \\
\hline
\end{tabular}

$\mathrm{RH}=$ relative humidity $[\%], T=$ temperature $\left[{ }^{\circ} \mathrm{C}\right]$.

Based on the tests in which the relative humidity was constant and the temperature varied, the coefficient of linear temperature expansion, as expected, was independent of the interval of temperature variation, as Table 8 indicates. We made this observation for both cement content of $4 \%$ and $5 \%$. In tests in which the temperature was constant and the relative humidity varied, the size of the strains approximately doubled when the range of the relative humidity variation was doubled. Again, we found this result for both cement contents. However, we observed no difference between the strains for a cement content of $4 \%$ and $5 \%$. 


\section{Discussion}

\subsection{Discussion of strength properties}

\subsubsection{Strength properties of sub-base gravel}

The compressive strength and splitting tensile strength are not typical parameters used to characterize sub-base gravel. Instead, the design of sub-base gravel pavements, and such, are typically based on Young's modulus. The determination of Young's modulus of gravel materials is very sensitive to the stiffness of the surroundings, and therefore, would be determined from large-scale falling weight deflectometer tests, which are often expensive and cumbersome to carry out. Therefore, in the design of constructions with sub-base gravel it is a common standard to use table values to characterize the material rather than actual measurements; thus, we find it reasonable to also use table values for this study. Danish road standards assume that Young's modulus is the same for both types of subbase gravel tested in this study, although they have a different gradation [34].

\subsubsection{Strength properties of cement-stabilized gravel}

As Table 4 shows, the 28-day compressive strength of cement-stabilized gravel with $4 \%$ cement and $5 \%$ was $6.2 \mathrm{MPa}$ and $12.3 \mathrm{MPa}$, respectively. This finding classifies $\mathrm{CG} 4 \%$ and CG5\% as belonging to strength classes $\mathrm{C}_{5 / 6}$ and $\mathrm{C}_{12 / 15}$, respectively, according to the DS 14227-1 standard [14]. Because the specimens were designed with gravel within envelopes B in the DS 14227-1 standard [14], Danish road standards prescribe that the initial Young's moduli for the particular strength classes are 11.5 GPa and 18.0 GPa for CG4\% and CG5\%, respectively, [34]. Young's moduli determined for the cementstabilized gravel in this study were slightly larger, but still consistent with the values in Danish road standards.

\subsubsection{Strength properties of pervious concrete}

For pervious concrete, the strength properties are highly dependent on the void content. Often a linear correlation between void content and strength properties is assumed with the strength decreasing as the void content increases [13]. In this study, a 28-day compressive strength of 9.9 MPa was obtained for a void content of $18.1 \%$, as shown in Table 4 . It is important to note that the void content of the specimens in this study expressed an average value of the voids inside the specimens. In fact, the void content varied throughout the specimen. Because compaction was applied from the top, the void content of the specimens was lowest at the top and increased down through the specimen. This finding also explains why the specimens for permeability and freeze-thaw testing cut from the upper and lower part of the cylinder specimens had different void contents and why it was not possible to test specimens with similar void contents in all types of tests. In fact, the strength properties were connected with the part of the specimen having the highest void content, that is, the bottom of the specimens, which had a void content higher than $18.1 \%$. However, correlating the strength properties of pervious concrete with the average void content is a common practice.

\subsubsection{Comparison of strength properties}

Young's modulus of sub-base gravel is less by a factor of $10^{2}$ than Young's modulus of cement-stabilized gravel and pervious concrete because the material does not contain any cement. Hence, of all the tested materials, the sub-base gravel fill had the poorest bearing capacity. However, in constructions in which the fill material serves only to stabilize the arch structure and transfer the vertical loads from the road surface to the arch structure, the stiffness requirements are very low, and Young's modulus for sub-gravel fill is typically sufficient. On the other hand, in arch bridge constructions in which the fill has a structural purpose and should be designed to carry, for example, shear stresses, a sub-base gravel fill is inappropriate. Instead, either cement-stabilized gravel or pervious concrete provides improved strength properties and bearing capacity.

The 28-day compressive strength and the 28-day Young's modulus of pervious concrete fell between the corresponding values for cement-stabilized gravel with $4 \%$ and $5 \%$ cement. The 28-day splitting tensile strength for pervious concrete was $42 \%$ less than for cement-stabilized gravel containing $4 \%$ cement. For pervious concrete, we considered only a single mix design void content of $17.5 \%$ in this study; hence, only cylinders with a single void content were tested in compression. If the void content were decreased, the strength properties would be expected to increase accordingly. However, these results indicated that the strength properties of pervious concrete and cement-stabilized gravel are comparable.

\subsection{Discussion of permeability}

\subsubsection{Permeability of sub-base gravel}

When considering the permeability of sub-base gravel as shown in Table 5, note that the determination of the permeability was performed on specimens with a compaction degree of approximately $100 \%$. Typical values for the permeability of gravel materials are given for loosely compacted specimens; however, according to Lambe and Whitman [35] the permeability is minimum at maximum compaction, which means that the values in Table 5 are less than most table values. We believe, the permeability of $0-32 \mathrm{~mm}$ sub-base gravel was larger than the permeability of $0-8 \mathrm{~mm}$ sub-base gravel because the tortuosity of the pore system is less for 0-32 $\mathrm{mm}$ sub-base gravel, as discussed in Lund et al. [20].

\subsubsection{Permeability of cement-stabilized gravel}

As far as we could ascertain, very little literature exists on permeability of cement-stabilized gravel, and we could not find comparable results. Our results indicate that permeability decreases when increasing cement content because the fines content is increased.

\subsubsection{Permeability of pervious concrete}

The permeability coefficient of pervious concrete is highly dependent on the void content; however, the void contents of $9.3 \%$ and $20.2 \%$ considered in the permeability tests in this study represent the expected void content limits for pervious 
concrete fill in Pearl-Chain Bridges. Typically, the permeability coefficient of pervious concrete with a void content between $15-20 \%$ is between $0.20-0.54 \mathrm{~cm} / \mathrm{s}$ [23], and our results agreed with this expectation.

\subsubsection{Comparison of permeability}

The permeability coefficients of sub-base gravel, cementstabilized gravel, and pervious concrete vary substantially. Pervious concrete, the most permeable material we tested, has a permeability coefficient that is a factor of $10^{2}$ times larger than the permeability coefficient of sub-base gravel, and a factor of $10^{6}$ times larger than the permeability coefficient of cementstabilized gravel, the least permeable material tested.

In Denmark the maximum intensity of a rain event with a 1 -year return period is $2.5 \times 10^{-3} \mathrm{~cm} / \mathrm{s}$ [36]. The tested $0-32$ $\mathrm{mm}$ sub-base gravel specimens could exactly drain the water from a rain event with a 1 -year return period; however, the $0-8$ mm sub-base gravel specimens could not. The permeability of the cement-stabilized gravel specimens that we tested was also too low to drain that amount of rainwater. However, the permeability of the pervious concrete specimens was large enough to drain this maximum intensity instantaneously. In fact the pervious concrete specimens tested were permeable enough to instantaneously remove water from a rain event with a 100-year return period in Denmark [36].

\subsection{Discussion of freeze-thaw durability}

\subsubsection{Freeze-thaw durability of sub-base gravel}

According to Danish tender specifications, the sub-base gravel materials tested in this study are not expected to be frostsusceptible [12] because their fines content is low. However, we found that $0-32 \mathrm{~mm}$ sub-base gravel had a medium frost susceptibility, and therefore, could be expected to experience a certain degree of frost heaving. On the other hand, results indicated that the frost susceptibility of $0-8 \mathrm{~mm}$ sub-base gravel is negligible. The difference in frost susceptibility seemed to be correlated to the difference in permeability; thus, our results indicated that the freeze-thaw damages of sub-base gravel can be minimized by carefully selecting a material with low fines content and a small permeability.

The applied test method for determination of the frost susceptibility was chosen because it is the only well-known method to determine the frost susceptibility of gravel; however, the test method assumes a constant water table below the gravel specimen. Considering the permeability of sub-base gravel (Section 4.2.4) such water table is only expected below a subbase gravel fill in arch bridges under extreme conditions. This is because, in most cases, the permeability of sub-base gravel is large enough to drain penetrating rainwater and furthermore, the arch shape naturally directs water that penetrates the fill towards the bridge ends. Therefore, in general, a sub-base gravel fill is not expected to experience problems with frost heave.

\subsubsection{Freeze-thaw durability of cement-stabilized gravel}

As shown in Figure 9, the presence of salt ions had a significant influence on the freeze-thaw durability of cementstabilized gravel, and the impact was greatest for specimens containing $4 \%$ cement compared with $5 \%$ cement. The compressive strength decreased $25.4 \%$ and $19.2 \%$, respectively, after 56 frost cycles, compared with the reference specimens. When demineralized water was used, the compressive strength decreased $14.6 \%$ and $7.7 \%$ for specimens with $4 \%$ and $5 \%$ cement, respectively, after 56 frost cycles. For all specimens exposed to salt ions, the decrease in compressive strength after 20 frost cycles was similar to the decrease in compressive strength after 56 frost cycles. Hence, the major part of the deterioration took place in the early frost period. We did not observe the same tendency for the specimens exposed to demineralized water in which a larger reduction in compressive strength was observed after 56 frost cycles compared with 20 frost cycles. After 20 frost cycles, the specimens with 5\% cement exposed to demineralized water had not experienced any change in compressive strength compared with the reference specimens. For a cement content of $4 \%$ this change also was minor. Overall, the results indicated that addition of $5 \%$ cement compared with $4 \%$ increased the frost resistance of cement-stabilized gravel with respect to compressive strength. This result also was supported by the measurements of the ultrasonic wave speed shown in Table 7. Specimens exposed to demineralized water experienced a smaller decrease in wave speed than specimens exposed to a $3 \% \mathrm{NaCl}$ solution, and specimens with $5 \%$ cement experience a smaller decrease in wave speed than specimens with $4 \%$ cement.

We believe that the applied test method for determination of the freeze-thaw behavior of cement-stabilized gravel is representative of the behavior of a cement-stabilized gravel fill material. The permeability results (Section 4.2.4) indicated that cement-stabilized gravel fill can be expected to become water saturated and due to freeze-thaw, this can cause a severe reduction in the compressive strength of the fill.

\subsubsection{Freeze-thaw durability of pervious concrete}

The mass loss of the pervious concrete specimens exposed to freezing and thawing was the easiest indication of the extent of freeze-thaw damages of the specimens. First, specimens exposed to a $3 \% \mathrm{NaCl}$ solution experienced a greater mass loss than specimens exposed to demineralized water, as Figure 10 indicates. Second, the mass loss of the specimens exposed to the drained method was as large as the mass loss of the specimens exposed to the saturated method. Finally, the mass loss of the bottom specimens was larger than the mass loss of the top specimens; that is, the specimens having the largest void content were most exposed to deterioration during freeze-thaw. Also, those tendencies could be clearly visually observed, as Figure 11 indicates. Whereas only minor damages were observed for the specimen exposed to demineralized water, larger damages were observed for the specimen exposed to a $3 \% \mathrm{NaCl}$ solution. Schaefer et al. [13] used a mass loss of $15 \%$ to represent the terminal serviceability acceptable level. None of the mass loses in Figure 10 exceeded this limit.

The mass loss made it difficult to determine the compressive strength for specimens exposed to 24 frost cycles and 56 frost cycles because the end surfaces were deteriorated, especially for the specimens exposed to salt ions. Hence, the decrease in 
compressive strength was not an appropriate method to assess the freeze-thaw durability of pervious concrete.

Although we used air entrainment to improve the freeze-thaw durability of the pervious concrete specimens, the specimens nevertheless experienced frost damage. The reason might be that the amount of air entrainment added to the mix was insufficient for the applied test method. We determined the necessary amount of air entrainment from press-ur-meter readings as for conventional concrete. However, the amount added might have been too low. Studies have indicated that press-ur-meter readings of entrained air in pervious concrete can be incorrect because air caught in the large voids is also included [37].

The applied testing procedure is not very representative for the freeze-thaw behavior of a pervious concrete fill. This is because such fill is not expected to be water saturated at any time after placement because of the large permeability of pervious concrete (Section 4.2.4); hence, the applied test procedure is too harsh. For pervious concrete, several studies have shown that air-entrained pervious concrete performs well in the field in areas that undergo several frost cycles per year because the water drains away [38]. In practice, we believe that the recorded levels of freeze-thaw durability are sufficient for a pervious concrete fill.

\subsubsection{Comparison of freeze-thaw durability}

All tested materials showed damages due to freezing and thawing under the applied test procedures; however, not all test procedures were good representations of the freeze-thaw behavior of fill in arch bridges. We believe that cement-stabilized gravel is very much exposed to freeze-thaw damages if implemented as fill in arch bridges, whereas pervious concrete fill has sufficient freeze-thaw durability because water is entirely prevented from accumulating in the fill. Sub-base gravel fill is in general not expected to experience problems with frost heave; however, because the permeability of sub-base gravel is much lower than of pervious concrete, there is a risk for water accumulation in the fill and thereby a constant water table can build up below the fill. In such case frost heave of the fill might occur.

\subsection{Discussion of shrinkage}

In this study, we determined shrinkage behavior for cementstabilized gravel only. Although literature has described that the shrinkage behavior of cement-stabilized gravel as a major concern that can cause shrinkage cracking, so-called reflection cracking, the underlying phenomena are not well-understood or well-described. Today, the most common method to prevent reflection cracking of cement-stabilized pavements is crack control in which cracks are cut halfway through the cementstabilized gravel layer every $2 \mathrm{~m}$. However, this solution is not economical attractive. Several factors influence the shrinkage properties of cement-stabilized gravel, such as the mix design and the degree of compaction. However, for specimens of a given mix design, two main parameters are believed to influence the shrinkage behavior: variation in temperature and variation in relative humidity. The results shown in Table 8 indicate that the size of the strains induced by a variation in relative humidity was an order of magnitude less than that of the strains induced by a variation in temperature. Therefore, shrinkage cracking observed for cement-stabilized pavements is mainly explained by temperature-dependent rather than moisture-dependent shrinkage. Table 8 also indicates that for both cement contents we tested, the coefficient of linear temperature expansion was similar to that of conventional concrete that has a coefficient of linear temperature expansion of $10 \times 10^{-6}{ }^{\circ} \mathrm{C}^{-1}$ for a cement-to-aggregate ratio of 1:6 [39]. As the cement content of cement-stabilized gravel increases the coefficient of linear temperature expansion increases, which aligns with findings of Neville [39]. The values listed in Table 8 relate to a cement-stabilized gravel fill placed on a concrete arch that is rigid and does not move due to creep, relaxation, and temperature expansion. This is a simplification, and in reality it is expected that movements of the concrete arch cause a build-up of stresses in the fill which should also be considered; however, this is outside of the scope of the present study.

For pervious concrete, the literature has shown that cracking caused by shrinkage is not a concern and that many pervious concretes are made without control joints [23]. Again, considerations on the shrinkage behavior of pervious concrete fill should not be isolated but correlated to the movements of the concrete arch.

\subsection{Pros and cons of different fill materials}

Based on the findings in this study, we can summarize the advantages and disadvantages of using either sub-base gravel, cement-stabilized gravel or pervious concrete as fill material in arch bridges as shown in Table 9. Table 9 also includes parameters not previously discussed in this paper, such as considerations of cost and placing technique.

Economy is an essential consideration in all construction projects and therefore should be included when discussing pros and cons of different fill materials. Sub-base gravel is the least expensive fill material, and therefore the most attractive choice if price is the only consideration. On the other hand, pervious concrete is the most expensive fill. However, economic aspects should not be based on the prices alone, but must be seen in a broader perspective and over the entire lifespan of the bridge because materials with better durability require less maintenance.

When placing sub-base gravel and cement-stabilized gravel, the material must be placed in layers no thicker than $30 \mathrm{~cm}$ in order to provide necessary compaction. Studies have shown that it is possible to design self-compacting pervious concrete [40]; therefore, we can assume that it would be possible to design a self-compacting pervious concrete mix that could be cast simply by pouring it onto the arch in a single lift and compacting it only from the top. Such an approach would be highly attractive because it would minimize the work involved in placing the fill.

\subsection{Applicable fill materials for Pearl-Chain Bridges}

Based on the advantages and disadvantages of the three different fill materials listed in Table 9, the following fill materials are found to be applicable in Pearl-Chain Bridges: 
Table 9: Pros and cons of using sub-base gravel fill, cement-stabilized gravel fill, and pervious concrete fill in arch bridges.

\begin{tabular}{lll}
\hline Fill material & Pros & Cons \\
\hline Sub-base gravel & - Low material price & - Poor shear strength \\
& - Reasonable permeability & - Maximum layer thickness of $30 \mathrm{~cm}$ \\
& - Reasonable freeze-thaw durability & \\
\hline Cement-stabilized gravel & - Relatively low material price & - Poor permeability \\
& - Good strength properties & - Poor freeze-thaw durability \\
& - Shear transferring & - Maximum layer thickness of $30 \mathrm{~cm}$ \\
& & - Reflection cracking (need for control joints) \\
\hline Pervious concrete & - Good strength properties & - High material price compared to sub-base gravel \\
& - Shear transferring & and cement-stabilized gravel \\
& - Excellent permeability & \\
& - Sufficient freeze-thaw durability & \\
& - Self-compacting and easy to place (not tested in & \\
& the present study) & \\
& - No need for control joints (not tested in the & \\
& present study) & \\
\hline
\end{tabular}

1. Pearl-Chain Bridges without sandwich effect:

- Sub-base gravel or pervious concrete.

In Pearl-Chain Bridges without the sandwich effect (no concrete top plate), the shear transferring properties of pervious concrete are not needed and the strength properties of sub-base gravel are sufficient. However, this study has shown that the permeability of pervious concrete is much improved in comparison to sub-base gravel. We believe this is an important factor concerning the durability of the bridges because penetrating water is entirely prevented from accumulating in a pervious concrete fill. Despite the higher material price, pervious concrete is a strong and reasonable alternative to sub-base gravel considering the entire life span of the bridges.

\section{Pearl-Chain Bridges with sandwich effect (concrete top} plate):

- Pervious concrete.

For this type of arch bridge construction, the fill material needs to transfer shear stresses and therefore pervious concrete is recommended. Compared to cement-stabilized gravel it has much improved freeze-thaw durability and permeability which positively influence the lifespan of the bridge.

\section{Conclusions}

In this study, we tested and compared the strength and durability properties of three different fill materials. These materials included two types of sub-base gravel with gradations of 0-8 $\mathrm{mm}$ and $0-32 \mathrm{~mm}$, two types of cement-stabilized gravel with $0-16 \mathrm{~mm}$ gravel mixed with $4 \%$ and $5 \%$ cement, and one type of pervious concrete with a mix design void content of $17.5 \%$. The final choice of the most appropriate filling material for an arch bridge depends on several factors, such as the static system of the bridge, the total maximum thickness of the fill, and the surrounding climate. For Pearl-Chain Bridges without sandwich effect we found that either sub-base gravel or pervious concrete are applicable as fill, whereas for Pearl-Chain Bridges constructed as sandwich arches, only pervious concrete is applicable as fill. Cement-stabilized gravel is not recommended. These recommendations originate from the strength and durability properties we determined from the tested mixes:

1. The compressive strength and splitting tensile strength of cement-stabilized gravel was comparable to pervious concrete, according to measurements of 28-day compressive strengths and 28-day splitting tensile strengths of 6.2-12.3 $\mathrm{MPa}$ and 1.5-5.2 MPa, respectively.

2. Young's modulus of sub-base gravel is $0.150 \mathrm{GPa}$ according to Danish road regulations [34], which was less by a factor of $10^{2}$ than Young's modulus of cement-stabilized gravel and pervious concrete.

3. The permeability of pervious concrete was $10^{2}$ times larger than the permeability of sub-base gravel, and larger by a factor of $10^{6}$ than the permeability of cementstabilized gravel. The permeability of $0-32 \mathrm{~mm}$ sub-base gravel was large enough to drain the maximum intensity of a rain event with a 1-year return period in Denmark but neither 0-8 $\mathrm{mm}$ sub-base gravel nor cement-stabilized gravel could do so. However, the permeability of pervious concrete was large enough to drain the maximum intensity of a rain event with a 100-year return period in Denmark.

4. All tested materials showed damages due to freezing and thawing under the applied test procedures; however, the results should be seen in the light of how well these procedures represent the actual freeze-thaw situations for fill materials in arch bridges. It is expected that cementstabilized gravel is very much exposed to freeze-thaw damages if implemented as fill material, whereas the freeze-thaw durability of pervious concrete fill is expected to be sufficient. Sub-base gravel fill is not expected to experience problems with frost heave unless a constant water table builds up below the fill.

5. The shrinkage behavior is expected to be a durability con- 
cern only for cement-stabilized gravel. The shrinkage behavior for cement-stabilized gravel can mainly be explained by temperature-dependent rather than moisturedependent shrinkage, which is an order of magnitude less.

\section{Acknowledgments}

The authors wish to thank Innovation Fund Denmark for supporting this project.

\section{References}

[1] Bourke J, Taylor S, Robinson D, Long A. Analysis of a flexible concrete arch. In: Chen B, Wei J, editors. ARCH'10: Proceedings of 6th International Conference on Arch Bridges; 2012 Oct 11-13; Fuzhou, China. p. 133-39.

[2] Bernini J. Overfilled precast concrete arch bridge structures. Zürich: BEBO of America, Inc; 2000.

[3] Sihwa L. Computer data base assessment of masonry bridges [dissertation]. Edinburgh, UK: University of Edinburgh; 1987.

[4] Hutchinson D. Application and design of segmental precast arches. In: Yegian MK, Kavazanjian E, editors. Proceedings of Geo-Trans; 2004 Jul 27-31; Los Angeles. p. 452-59.

[5] BEBO Arch Systems. BEBO system technical documentation: Installation guide. Zürich: BEBO Arch Systems; 2009.

[6] Melbourne C. The testing of a mass concrete arch bridge. In: Garas FK, Armer GST, Clarke JI, editors. Building the future: Innovation in design, materials and construction. London: E \& FN Spon; 1993. p. 226-33.

[7] Long A, McPolin P, Kirkpatrick J, Gupta A, Courtenay D. FlexiArch: From concept to practical applications. The Structural Engineer, 2014;92(7):10-5.

[8] Halding PS, Hertz KD, Schmidt JW. Precast Pearl-Chain concrete arch bridges. J Eng Struct, 2015;103:214-27.

[9] Lund MSM, Arvidsson M, Hansen KK. Homogeneity and strength of mortar joints in Pearl-Chain Bridges. In: Proceedings of fib Symposium; 2015 May 18-20; Copenhagen. p. 187-88.

[10] Halding PS, Hertz KD, Petersen NEV, Kennedy B. Assembly and lifting of Pearl-Chain arches. In: Proceedings of fib Symposium; 2015 May 1820; Copenhagen, Denmark. p. 185-86.

[11] Lund MSM, Hansen KK, Truelsen R, Johansen L. Pervious concrete fill in Pearl-Chain Bridges: Using small-scale results in full-scale implementation. Constr Build Mater. 2016;106:404-14.

[12] Danish Road Directorate. Sub-base of sand and gravel-Design guide. Tender specification. Copenhagen: The Directorate; 2003, ISBN: $87-$ 7923-502-6. Danish.

[13] Schaefer VR, Wang K, Suleiman MT, Kevern JT. Mix design development for pervious concrete in cold weather climates. Ames, IA: National Concrete Pavement Technology Center and Iowa State University; 2006.

[14] DS Standard 14227-1. Hydraulically bound mixtures - Specifications Part 1: Cement bound granular mixtures. Copenhagen: Danish Standards; 2004.

[15] DS Standard 13286-5. Unbound and hydraulically bound mixtures - Part 5: Test methods for laboratory reference density and water content - Vibrating table. Copenhagen: Danish Standards; 2003.

[16] DS Standard 13286-2. Unbound and hydraulically bound mixtures - Part 2: Test methods for laboratory reference density and water content - Proctor compaction. Copenhagen: Danish Standards; 2011.

[17] Lund MSM, Hansen KK, Hertz KD. Frost resistance and permeability of cement stabilized gravel used as filling material for Pearl-Chain Bridges. In: Bastien J, Rouleau N, Fiset M, Thomassin M, editors. Proceedings of 10th fib International PhD Symposium in Civil Engineering; 2014 Jul $21-$ 23; Québec, Canada. Québec: Research Center on Concrete Infrastructure (CRIB), Université Laval; 2014. p. 155-60.

[18] Lund MSM, Hansen KK, Hertz KD. Experimental study of properties of pervious concrete used for bridge superstructure. In: Proceedings of 12th International Symposium on Concrete Roads; 2014 Sep 23-26; Prague.

[19] ASTM Standard D5918-13. Standard Test Methods for Frost Heave and Thaw Weakening Susceptibility of Soils. West Conshohocken, PA: ASTM International; 2013. doi: 10.1520/D5918-13.
[20] Lund MSM, Hansen KK, Andersen IB. Frost Susceptibility of Sub-base Gravel used in Pearl-Chain Bridges: An Experimental Investigation. Int J Pavement Eng, Forthcoming 2016.

[21] EN Standard 13286-50. Unbound and hydraulically bound mixtures Part 50: Method for the manufacture of test specimens of hydraulically bound mixtures using Proctor equipment or vibrating table compaction. Brussels: European Standards; 2011.

[22] Danish Road Directorate. Hydraulic bound layers-General work specification (GWS). Tender specification. Copenhagen: The Directorate; 2009, ISBN: 978-87-7060-129-0. Danish.

[23] Tennis PD, Leming ML, Akers DJ. Pervious concrete pavements. EB302.02, Skokie, IL: Portland Cement Association, and Silver Spring, MD: National Ready Mixed Concrete Association; 2004.

[24] EN Standard 13286-41. Unbound and hydraulically bound mixtures Part 41: Test method for the determination of the compressive strength of hydraulically bound mixtures. Brussels: European Standards; 2003.

[25] EN Standard 13286-43. Unbound and hydraulically bound mixtures Part 43: Test method of the modulus of elasticity of hydraulically bound mixtures. Brussels: European Standards; 2003.

[26] DS Standard 12390-3. Testing hardened concrete - Part 3: Compressive strength of test specimens. Copenhagen: Danish Standards; 2009.

[27] ISO Standard 6784. Concrete - Determination of static modulus of elasticity in compression. London: International Standard; 1984.

[28] EN Standard 13286-42. Unbound and hydraulically bound mixtures Part 42: Test method for the determination of the indirect tensile strength of hydraulically bound mixtures. Brussels: European Standards; 2003.

[29] ISO Standard 4108. Concrete - Determination of tensile splitting strength of test specimens. London: International Standard; 1980.

[30] ASTM Standard D2434-68. Standard Test Method for Permeability of Granular Soils (Constant Head). West Conshohocken, PA: ASTM International; 2006. doi: 10.1520/D2434-68R06.

[31] prEN Standard 13286-54. Unbound and hydraulically bound mixtures Part 54: Test method for determination of frost susceptibility - Resistance to freezing and thawing of hydraulically bound mixtures. Brussels: European Standard; 2011.

[32] SS Standard 137244. Concrete testing - Hardened concrete - Scaling at freezing. Stockholm: Swedish Standards; 2005.

[33] Lund MSM, Hansen KK. Shrinkage properties of cement stabilized gravel. In: The Nordic Concrete Federation, editors. Proceedings of XXII Nordic Concrete Research Symposium; 2014 Aug 13-15; Reykjavik. Oslo: Norsk Betongforening; 2014. p. 303-06.

[34] Danish Road Directorate. Design of pavements and reinforcement layers. Handbook. Construction and planning. Copenhagen: The Directorate; 2013. URL: http://englishvejregler.lovportaler.dk/ShowDoc.aspx?q=Design+of+pavements+and+ reinforcement+layers\&docId=vde-2015-0060-full

[35] Lambe TW, Whitman RV. Soil mechanics. New York: John Wiley \& Sons; 1969.

[36] IDA Wastewater Commission. Regional variation of extreme rain in Denmark - a new analysis, 1979-2005. Pamphlet No. 28. Copenhagen: The Commission; 2006. ISBN: 87-7923-502-6. Danish.

[37] Kevern JT, Wang K, Schaefer VR. Test methods for characterizing air void systems in Portland cement pervious concrete. J ASTM Int. 2009;6(9):119-34. doi:10.1520/JAI102451.

[38] National Ready Mixed Concrete Association (NRMCA). Freeze-thaw resistance of pervious concrete. Silver Spring, MD: NRMCA; 2004.

[39] Neville AM. Properties of concrete. 4th ed. Essex: Pearson Education Limited; 1995.

[40] Kevern JT. Self-consolidating pervious concrete: A discussion of material properties and behaviors. In: Proceedings of the Fifth North American Conference on the Design and Use of Self-Consolidating Concrete; 2012 May 12-15; Chicago. 